\title{
Polysaccharides from Larch Biomass
}

\author{
Natalya Nikolaevna Trofimova, Elena Nikolaevna Medvedeva, \\ Nadezhda Viktorovna Ivanova, Yuriy Alekseevich Malkov \\ and Vasiliy Anatolievich Babkin
}

Additional information is available at the end of the chapter

http://dx.doi.org/10.5772/53809

\section{Introduction}

There are two species of the genus Larix Mill, Larix sibirica Ledeb. (Figure 1) and Larix gmelinii (Rupr.) Rupr., considered to be the most abundant trees in the Russian Federation: the total stock of their wood exceeds 26 billion $\mathrm{m}^{3}$. Traditionally, the main economic value of larch wood consists of the manufacture of roundwood (timber), the value of which is connected with the high quality of lumber from this breed of tree. Larch wood can sometimes be used in insignificant quantities in pulp-and-paper manufacture to obtain pulp. About $40 \%$ of this valuable breed (as bark, sawdust) enters waste through existing lumber manufacturing processes. Such an irrational approach to the development of larch wood does not allow exploitation of the richest potential of the given renewed source. Meanwhile, biologically active compounds contained in larch biomass can be used for the manufacture of products for medical, food and agricultural purposes with maximal benefit. The development of complex technology for chemical processing of larch biomass and waste timber will considerably raise the economic value of this biological resource.

This chapter is devoted to polysaccharides contained in the wood and bark of larch, i.e. heteropolysaccharide arabinogalactan (AG) and pectin polysaccharides (pectin substances, PS). The chapter also deals with the development of technologies for the preparation of these polysaccharides and the study of their useful properties. Wood hemicelluloses and cellulose represent a potential source of valuable monosaccharides, namely glucose, which can be readily obtained by hydrolysis transformation of these polysaccharides.

Larch wood contains a high quantity of arabinogalactan, a considerable part of which can be found in the butt of a tree, which frequently enters waste. Arabinogalactan possesses a wide spectrum of biological activity. It shows immunomodulating activity, gastroprotective, membranotropic and prebiotic properties, and can be used in the medical, veterinary, food 
and cosmetic industries. Arabinogalactan is a perspective matrix for obtaining on its basis metal-, sulpho-, amino- and other derivatives due to the reactive hydroxyl and aldehyde groups contained in its molecule. The ability of arabinogalactan to form water-soluble stable substances with inorganic nanoparticles and low-molecular medical substances (MS) provides serious prospects for the development of materials with unique properties.
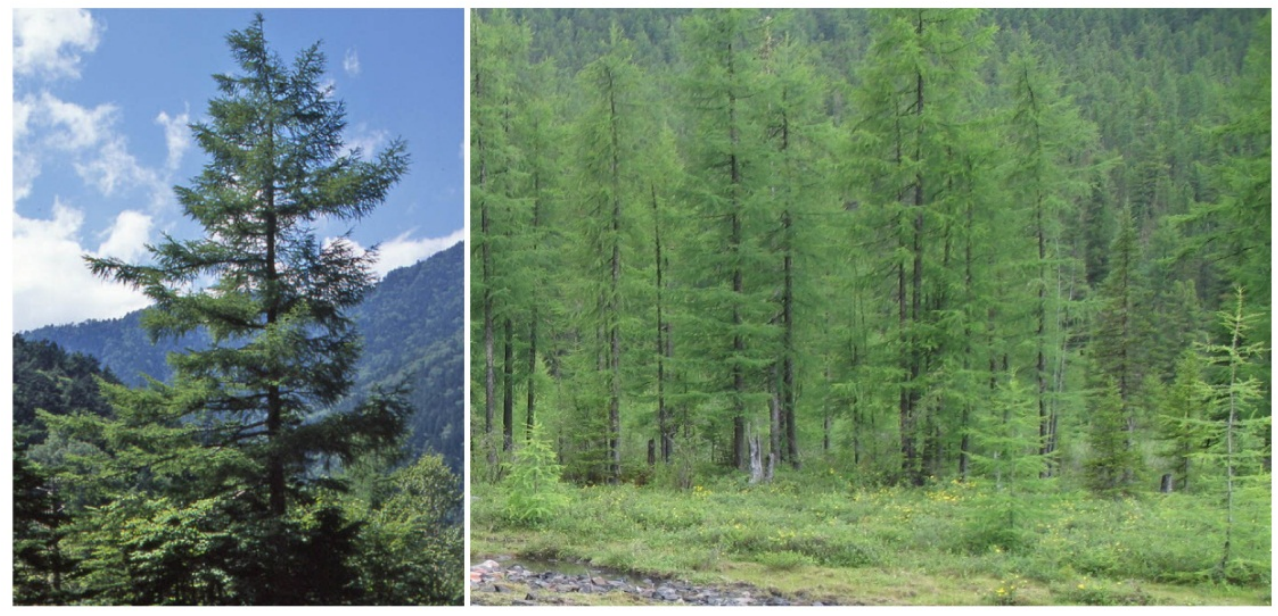

Figure 1. Larix sibirica Ledeb.

In the USA, arabinogalactan has been extracted from the wood of L. occidentalis Nutt. and $L$. laricina (Du Roi) by K. Koch for more than 40 years as a commercial product. Effective immunity-modulating and prebiotic biologically active food additives have been developed to improve quality of human life. Application of arabinogalactan in agriculture as fodder additive allows the greater efficiency of animal industries. Arabinogalactan is not currently manufactured in Russia.

The bark of larch does not however have industrial application. Annually, wood-processing industries and pulp-and-paper enterprises waste more than 30 million $\mathrm{m}^{3}$ in volume. It has become a serious environmental problem because the bark is badly exposed to biodegradation. At the same time, the chemical compounds of the bark can be a source of valuable biologically active substances, including polysaccharides. The creation of medical, food and other useful products on the basis of polysaccharides is also possible.

Larch bark contains about $7-12 \%$ of pectin polysaccharides, based on the weight of absolutely dry raw material. Pectin is acid polysaccharide-glycogalacturonane, and is contained in practically all plants. It is obtained from diverse sources that differ in their chemical structure due to distinctions in the qualitative structure of carbohydrates and their quantitative parities. Pectin substances promote digestive processes, and help organisms to resist many diseases such as atherosclerosis, diabetes, cancer, etc. There are two basic sources of pectin production in Germany and Denmark. However, there is no industrial production of pectin in Russia. 
As one of the possible sources of polysaccharides, cellulose-lignin residue can be formed by the extraction of polyphenolic substances from larch wood in the scheme for complex processing of larch biomass. Its chemical processing allows carbohydrate products to be produced, mainly crystalline glucose. Glucose is contained, mainly in the bound form, in considerable amounts of natural products as a constituent of various glycosides and polysaccharides. Taking into consideration that about $40 \%$ of the dry substance of plant mass is accounted for by cellulose formed by photosynthesis at a rate of about $70 \mathrm{~kg} /$ day per each inhabitant of our the planet, glucose is the most abundant sugar in nature.

All developed technologies are environmentally friendly. They are focused on processing of timber and industrial wood-processing waste, and possess high technical and economic parameters.

\section{Larch Arabinogalactan}

\subsection{Physicochemical and biological properties of Arabinogalactan}

Larch wood is distinctive for its high content of water soluble polysaccharide arabinogalactan, reaching up to $35 \%$ by weight of dry wood [1]. This valuable substance has been studied since the 1950s [1-6]. The physicochemical and biological properties of AG from the wood of L. occidentalis Nutt. and Siberian larch species L. sibirica Ledeb. and $L$. gmelinii (Rupr.) Rupr. are the most explored. The wood of Siberian larches contains up to $10-15 \%$ of AG [2,7] and is a reliable source of industrial raw material for AG production.

The AG macromolecule from larch wood has a highly branched structure. Its main chain consists of $\beta-(1 \rightarrow 3)$ linked galactose residues (Figure 2). Approximately one half of the side chains (in L. occidentalis Nutt., L. sibirica Ledeb. and L. gmelinii (Rupr.) Rupr.) is formed of $\beta$ $(1 \rightarrow 6)$-linked dimers of galactopyranose; galactopyranose monomers comprise about a quarter; and the remainder contains the major part of the polysaccharide's arabinose in aggregates of two or more monomers $[1,8,9]$. Arabinose fragments mainly occur as side chains consisting of 3-O-substituted $\beta$-L-arabinofuranose residues and terminal residues of $\beta$-L-arabinopyranose, $\beta$-D-arabinofuranose and $\alpha$-L-arabinofuranose $[8,9]$. However, arabinose fragments have also been found in the main chain [1]. Glucuronic acid fragments in AG from wood of various larch species is low in content. As for AG from the above species, no glucuronic acid fragments have been detected in the purified samples [6].

Monosaccharide composition and molecular mass (MM) of AG macromolecules differ among the species and also varies within single species. It has been established that the composition of AG macromolecules is dependent on the conditions under which it is isolated from larch wood and on the purification procedure $[9,10]$ as well as on molecular weight [1,11]. AG macromolecules have low molecular weights (13-20 kDa, according to HPLC data) and a narrow molecular weight distribution (degree of polydispersity 1.1-2.3) [10].

Biological activity of AG in higher plants is directly linked to their structural characteristics, such as length of galactan chain, structure of side chains, molecular weight and ability to form intermolecular associates $[12,13]$. Larch AG is characterized by low toxicity, showing 
neither acute poisoning for doses of $5 \mathrm{~g} / \mathrm{kg}$ nor chronic poisoning for doses of $500 \mathrm{mg} / \mathrm{kg}$ per day [14]. Diverse biological activity of AG includes immunomodulatory, prebiotic, hypolipidemic, gastro- and hepatoprotective, mitogenic, antimutagenic and antiviral effects, etc. There are reports on the inhibitory and destructive action of AG against certain types of malignant tumours [6,15-22]. Moreover, it has a good solubility in cold water, uniquely low viscosity of concentrated aqueous solutions, an ability to bind fat and retain liquid and dispersive capacity, etc. All these benefits are in high demand in medicine and veterinary science as well as in food and cosmetic industries [5,6]. There are a number of biologically active food supplements which incorporate AG [23-25]. In medicine, an ophthalmic composition (eye drops/contact lens care solution) has been developed [26]. Membranotropicity caused by galactose fragments and realized through receptor mediated endocytosis makes AG a promising drug carrier to increase absorbability and selectivity of medical substances that are characterized by low bioavailability [27-36]. Applications of AG in photodynamic diagnostics, in oncological disease therapy and in gene therapy (targeted delivery of functional genes) are currently being explored [37-39]. The unique properties of AG are prominent among the known polysaccharide carriers of medical substances $[40,41]$.

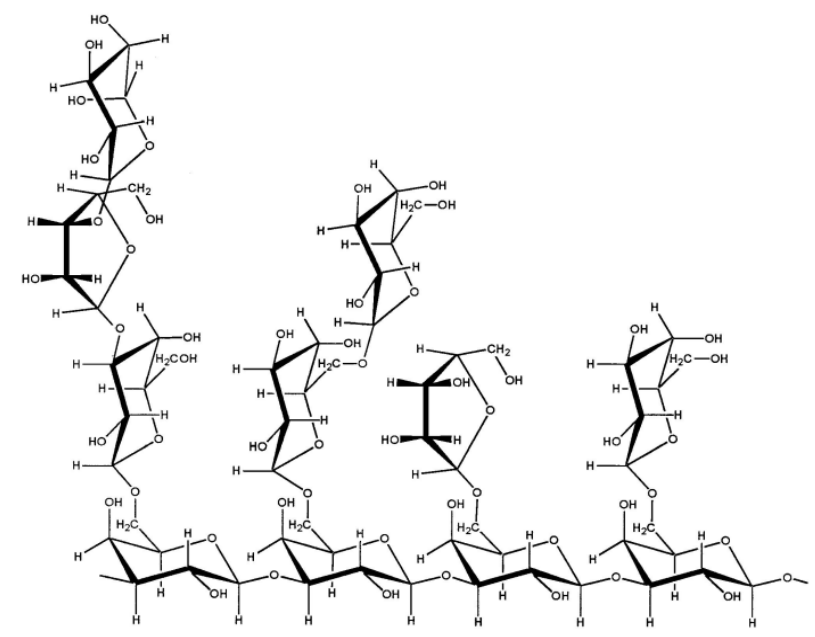

Figure 2. Structural fragment of AG macromolecule

Significant interest for medicine is raised by the products of AG modification [6]. Introducing diverse functional groups into the AG macromolecule makes it a manifold synthone to obtain a wide range of new biologically active substances. Oxidation is a promising way to functionalise AG. Methods of selective oxidation developed in classical carbohydrate chemistry [42] have been used to develop functionalized AG products [43,44]. Among others, oxidative destruction with simultaneous introduction of carboxylic groups into the macromolecule under the action of hydrogen peroxide in aqueous medium has been carried out [45]. It has been revealed that oligomeric products show anti-inflammatory and antiulcer activities. Reactions of AG and oxidized AG with some known MS give 
intermolecular complexes [46-48]. Such complexes of AG with 5-aminosalicylic acid show high antiulcer activity, while complexes incorporating 4-aminosalicylic or isonicotinic acid hydrazide demonstrate an antituberculosis effect. It has been established that conjugates of AG and products of its modification increase the physiological effect of MS and decrease their toxicity [28,46-48]; for instance, a conjugate of AG (9kDa) 9- $\beta$-Darabinofuranosyladenine-5'-monophosphate was 25-fold more active than the parent compound $9-\beta$-D-arabinofuranosyladenine ( $\operatorname{araA}$ ) in decreasing the amount of hepatitis $\mathrm{B}$ virus, and the toxicity of the complex preparation is much lower than araA [28]. To increase reactivity of AG with MS, the synthesis of conjugates proceeds by bromination, phosphorylation, amination, formation of hydrazides or reaction with $\mathrm{NaBH}_{4}[27,33,34]$.

Mechanochemical activation is another promising method of AG modification, in which the target products are obtained in one stage without the use of solvents. Mechanochemical treatment can give rise to numerous physicochemical transformations of AG macromolecules, which are associated, first, with the breaking and formation of valence bonds and, second, with the disturbance and origination of weak intermolecular interactions (disordering, conformational rearrangements, etc.). As a result, the polysaccharide can change its biological activity, toxicity and pharmacological properties. HPLC and quantitative ${ }^{13} \mathrm{C}$ NMR spectroscopy has established [49] that mechanochemical treatment of AG isolated from Siberian larch wood changes its molecular weight distribution, monosaccharide composition and degree of branching due to partial destruction of the macromolecules and subsequent recombination of their fragments. The extent of these changes depends on the activation conditions. The IR and ${ }^{13} \mathrm{C}$ NMR spectra have not shown any functionalization of AG macromolecules in the conditions studied. Toxicpharmacological study has established that a mechanochemically activated AG sample has the same LD50 (more $5000 \mathrm{mg} / \mathrm{kg}$ ) than the starting AG. As for the effect of mechanochemically activated AG upon the central nervous system, it has demonstrated anxiolytic activity similar to sibason in a dose of $20 \mathrm{mg} / \mathrm{kg}$ tested in laboratory animals. Meanwhile, single intravenous injection of the substance, in a dose of $3.5 \mathrm{mg} / \mathrm{kg}$, slightly but statistically significantly decreases arterial pressure (by 6\%) in normotensive rats without affecting electrocardiogram parameters and heart rate. Thus, mechanochemically activated AG is a promising drug carrier [49].

Combined mechanochemical activation of MS with AG (pharmacon clathration) is even more effective in improving safety and bioavailability of drugs [50-53]. Essentially (up to 50 times) increased solubility of MS and dramatically decreased therapeutic doses of the same efficiency are reported for clathrates of poorly soluble anti-inflammatory, psychotropic and hypotensive drugs [51,52]; for instance, clathrates of AG with nifedipine containing a 10 times lower dose than the starting MS show pronounced hypotensive and antiarrhythmic effects [52]. Additionally, the side effects of MS in clathrates are decreased, for instance in the ulcerogenity of nonsteroidal anti-inflammatory drugs. HPLC, ${ }^{13} \mathrm{C} N \mathrm{NMR}$ and IR spectroscopic studies have shown the absence of any chemical reaction between AG and MS at pharmacon clathration [51,53]. The X-ray phase study and thermal analysis prove the destruction of the crystal structure of MS and its dispersion within the AG matrix. The 
polysaccharide macromolecules are cleaved similarly to the mechanochemical activation of AG alone [49].

L. sibirica Ledeb. and L. gmelinii (Rupr.) Rupr. contain much bioflavonoid dihydroquercetin (DHQ, taxifolin) and their diverse biological activity is well studied. It is an officinal drug with a wide range of therapeutic action and is also the basis for a number of efficient medical preparations and food supplements [54]. Complexes of AG and DHQ combining these unique properties are very promising. Such complexes have been obtained by pharmacon clathration [54] and have shown essentially improved solubility (up to 38 times) in comparison with starting DHQ and untreated AG/DHQ mixture. No chemical reaction between AG and DHQ takes place, as in clathrates [51]. According to HPLC data, AG in $\mathrm{AG} / \mathrm{DHQ}$ clathrates has a narrower molecular weight distribution in comparison with pure mechanochemically activated AG, due to a decrease in both high- and low-molecular fractions, and thus DHQ stabilizes the polysaccharide macromolecules in mechanochemical treatment.

The most recent application of AG as a stabilizing polymer matrix in hybrid nanosized materials is based on iron oxides, cobalt, copper, nickel, ferrites and zero-valence metals such as silver, palladium and platinum [18,55-57]. Metal content in nanocomposite samples depends on synthetic conditions and on the type of metal ion used, varying in the range of $0.1-21.0 \%$. In the case of metal oxide nanocomposites, AG shows properties of a nanostabilizing matrix, while in the composites of noble metals it reduces metal to a zerovalence state and stabilizes the metal nanoparticles formed. Nanocomposites based on AG retain high biological activity. Ferroarabinogalactans show synergy between the pronounced antianaemic activity of the ferric core and the unique membranotropic and immunomodulatory properties of AG. Parenteral administration of ferroarabinogalactan normalizes quantitative and qualitative characteristics of the erythrocyte system and iron depot level in animals (white rats) [18]. The original synthetic method of ferroarabinogalactan retains both membranotropic and immunomodulatory properties of AG. Studies of the natural effects of immunomodulators, together with the investigation of specific immunity to plague, have revealed that ferroarabinogalactan activates peritoneal macrophages in guinea pigs, in comparison with the animals' cells being immunized only with vital plague vaccine.

Antibiotic resistance of microorganisms has led to a new interest in silver preparations. The most efficient are preparations of ultradispersed silver. Highly dispersed (nanosized) particles increase bactericidal activity. It has been established that silver-containing nanocomposites with AG possess high antimicrobial activity against gram-negative enterobacteria (Escherichia coli, Salmonella typhimurium, Candida albigans, Bacillus subtilis and Staphyllococcus aureus) [57].

Thus, the method for synthesis of nanocomposites with available polysaccharide AG is an easy way to synthesize universal materials. The AG-based nanobiocomposites synergistically combine the properties of the stabilizing natural polysaccharide matrix and the nanocore materials. They are applicable as nanosized water-soluble enantioselective 
catalysts, magnet-controlled medical substances, materials for coherent and nonlinear optics, high-sensitivity optical markers, universal antimicrobial preparations, etc. The use of AG as a bioactive polysaccharide matrix participating in the processes of receptor-induced endocytosis leads to new approaches to therapy for metal deficiency states and to the development of new biomaterials of target action, which are in high demand in medicine and biology, both as controlled composite materials and as new water-soluble biodegradable metal-containing drugs.

At present, healthy diet is a question of public policy in all developed countries due to the undisputed role of food in public health, working capacity of people, adaptation, child growth and longevity. The increasing popularity of healthy diets has made manufacturers pay more and more attention to functional food, i.e. medically fortified food products. Food supplements and enriched products are becoming increasingly popular. Such products are functionalized by both natural substances (pectin, inulin, gum arabic, etc.) and semisynthetic compounds (lactulose, polydextrose, resistant starches, chitosan, etc.).

Larch arabinogalactan adds nutrition and function to beverages, snack foods, nutrition bars, and more [6,58]. Not only does AG function as a prebiotic fibre and immunity enhancer, it also retains moisture, enhances mouthfeel and bulk, and improves shelf stability. Because of AG's low-viscosity profile and emulsification-enhancing properties, the most immediate applications include refrigerated and non-refrigerated beverages, and beverage mixes. Interest has also been expressed in snack foods, bars, ready-to-eat cereals, yogurt/dairy products and baked goods. Commercially available larch AG-containing products include beverages and nutrition bars.

Not only does AG add nutrition, it also provides functional benefits. An independent food laboratory confirmed that the inclusion of AG improved white pan bread make-up, external symmetry and internal grain scores. Fat-free flour tortillas with AG showed better handling, taste and aroma than the control. AG is a low-calorie additive for artificial sweeteners. It delivers mouthfeel, taste and bulking attributes that are most like sugar.

In confectionery and baked goods, AG lowers water activity and aids flavour and oil retention. AG can be used in browning compositions for uncooked foods, in seasoning powders to improve flow and reduce hygroscopicity, and in starch-containing foods to inhibit swelling.

Recent clinical investigations of AG have demonstrated not only benefits to gastrointestinal health and immunity, but also a significant reduction in serum cholesterol, glucose and insulin levels [58,59]. This opens the door to potential heart health label claims and provides an option for consumers looking for foods that are beneficial in terms of body weight, blood glucose or blood insulin control.

AG benefits, as determined by human and animal clinical trials, have been observed as low as $1.5 \mathrm{~g} /$ day, or more specifically $20 \mathrm{mg} / \mathrm{kg}$ of body weight. AG has been found to be totally safe as a food ingredient. On average, finished products containing a minimum of $60 \mathrm{mg} / \mathrm{kg}$ of body weight or about $4.5 \mathrm{~g} /$ day is recommended for foods [58]. Using arabinogalactan 
additives isolated from Siberian larch, the authors of one study [60] examined the soft wheat flour quality and quantity of gluten, physical properties of the dough, and quality of finished bread, depending on the quantity of the added polysaccharide. The addition of $1 \%$ of arabinogalactan to flour causes a significant improvement in the qualitative indices of bread. In this case, AG is totally consumed in the course of bread making because it is utilized by yeast. It is recommended that bread quality can be improved when the flour incorporates $1 \%$ mass of AG. When 2-3\% of AG is added to flour, the AG content decreases. An excess of AG inhibits yeast growth, which leads to a decrease in bread quality.

The optimum compositions for AG-enriched bakery goods and pastry have been proposed [61,62]. It has been shown that when AG is added to flour in proportions of $1-5 \%$ by weight, bakery products are rich in dietary fibre of prebiotic and immunostimulating action, while their energy density is lower due to the decreased amount of sugar in the recipes. The AGenriched bakery and pastry products have a medical effect [59]. Production technology for AG-enriched prebiotic cultured milk products has been developed [63]. The efficiency of AG in veterinary medicine has been proven [64-67].

\subsection{Technology of AG production}

The only regular production of AG is realized in the USA where the raw materials are derived from L. occidentalis Nutt. [5,6]. The known AG production techniques are all based on extraction of the polysaccharide from larch wood particles (chips, shavings, sawdust) and differ in pre-treatment of the raw material, conditions of extraction and methods of purifying the extracts and the final product [10]. The extraction process is highly dependent on the wood reduction range. Sawdust (specific surface of $164 \mathrm{~cm}^{2} / \mathrm{g}$ ) yields almost $90 \%$ of AG during the first 10 min of extraction while chips (specific surface of $17 \mathrm{~cm}^{2} / \mathrm{g}$ ) yield only $10 \%$ [68]. To intensify extraction, mechanochemical activation of larch wood and its further treatment with superheated water steam ("autohydrolysis explosion") is proposed [69]. The AG yields increase significantly (more than twice) if larch sawdust extraction is conducted with microwave or pulse ultrasound activation. Microwave or shock-and-acoustic processing of sawdust allows $90 \%$ of AG extraction to be completed in 30-60 seconds [70]. The products of larch wood water extraction, together with AG, are various phenolic compounds (low-molecular and oligomeric flavonoids, lignans, lignine substances and tannins), making production of high purity AG a complicated problem [71,72]. Purification of $A G$ water extracts from those impurities is a current issue.

We propose a beneficial, economically and ecologically sound method to obtain dry $95-97 \%$ AG $[17,73]$. There are two main stages: first, extraction and purification of the extract, and second, dry product isolation. Every stage has been carefully studied and theoretically rationalized.

Study of extraction process kinetics is primarily aimed at determining duration of contact between the phases to give the target degree of isolation. Extraction kinetics data determine the geometry of the apparatus. AG water extraction proceeds in two stages, the first of which is fast and the second is slow (Figure 3). 


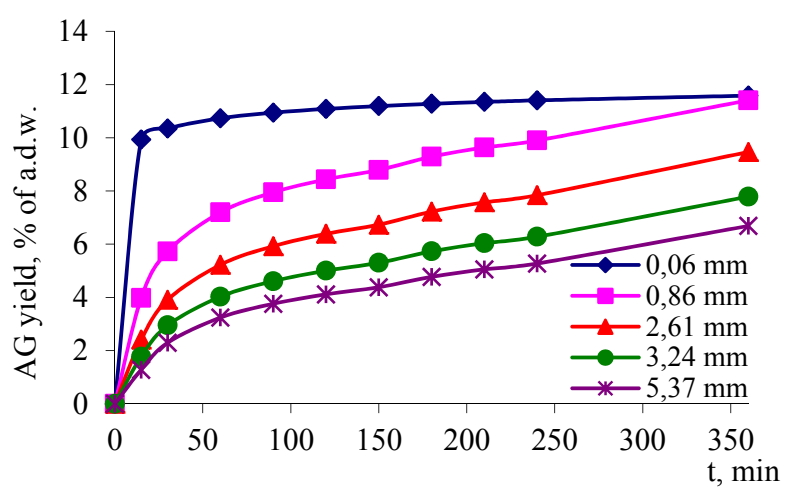

Figure 3. AG yield (\% of absolutely dry wood, a.d.w.), showing dependence on particle size

The extraction process is determined by AG diffusion and penetration of extracting solution into wood pores as well as by hydrodynamic conditions. Thirty minutes is sufficient to isolate almost the total amount of AG from sawdust, while, in the same conditions, wood chips need several days to yield the major fraction of AG. The quality of AG and other water-soluble components is not affected by wood reduction range.

On the basis of the experimental data, we calculated diffusion constants, mass-transfer coefficients and the Biot diffusion criterion (Bi), characterizing the influence of hydrodynamic conditions on AG isolation rate. For the extract $\left(Y_{p}\right)$, extraction was conducted until the equilibrium of the AG solution concentrations in wood pores reached equilibrium. As $\tau \rightarrow \infty$, Fourier diffusion criterion $\mathrm{Fo}_{g} \rightarrow \infty$. Thus, the kinetic equation of the extraction process can be described by the equation [74]:

$$
\frac{X-Y^{*}}{X_{s}-Y_{s}}=\sum_{n=1}^{\infty} A_{\mathrm{n}} \mathrm{e}^{-\mu_{n}^{2} F o_{g}}
$$

where $X$ is the average AG solution concentration in wood pores, at the moment of time $\tau$, $\mathrm{g} / \mathrm{cm}^{3} ; Y^{*}$ is the equilibrium concentration of the substance isolated in the solution, $\mathrm{g} / \mathrm{cm}^{3} ; X_{s}$ is the initial AG solution concentration in the wood pores, $\mathrm{g} / \mathrm{cm}^{3}$; and $Y_{s}$ - is the initial concentration of the substance isolated in the solution, $\mathrm{g} / \mathrm{cm}^{3}$;

$$
A_{n}=\frac{6 B i^{2}}{\mu_{n}^{2}\left(\mu_{n}^{2}+B i^{2}-B i\right)}
$$

where $\mu_{n}$ represents characteristic equation roots.

According to substance balance data,

$$
Y^{*}-Y_{i}=b\left(X-Y_{p}\right)
$$


where $Y_{i}$ is the concentration of the substance isolated in the solution at the moment of time $\tau, \mathrm{g} / \mathrm{cm}^{3}$; and

$$
b=\frac{G \varepsilon}{\rho V}
$$

where $G$ is the mass of the solid, $\mathrm{g}$; $V$ is the volume of the liquid phase, $\mathrm{cm}^{3} ; \rho$ is the density of the solid, $\mathrm{g} / \mathrm{cm}^{3} ; \varepsilon$ is the specific volume of wood pores occupied by solution, $\mathrm{cm}^{3} / \mathrm{cm}^{3}$.

The right side of the equation (3) determines the fraction of the substance transferred from the solid into the solution during the time interval from the moment under consideration until the end of the experiment. The left side determines the increase of the solution concentration during the interval mentioned. Substituting $\left(X-Y^{*}\right)$ into equation (1) according to (2) leads to:

$$
\frac{Y^{*}-Y_{i}}{X_{s}-Y_{s}}=\sum_{n=1}^{\infty} B_{\mathrm{n}} \mathrm{e}^{-\mu_{n}^{2} F o_{s}}
$$

where $\mathrm{B}_{\mathrm{n}}=\mathrm{bAn}$.

For a regular mode of extraction, the first member of the series in equation (5) is sufficient.

Figure 4 graphs the dependence of $\ln \frac{Y^{*}-Y_{i}}{X_{s}-Y_{s}}$ on $\tau$ according to equation (5), on the basis of experimental data.

Extrapolating the straight line (Figure 4) $f(\tau)=\ln \frac{Y^{*}-Y_{i}}{X_{s}-Y_{S}}$ to $\tau=0$ gives a diffusion constant, according to the equations:

$$
\operatorname{tg}(\alpha)=-\mu_{1}^{2} \frac{\mathrm{D} \tau}{l^{2}}
$$

and

$$
\operatorname{tg} \mu_{1}=\frac{\mu_{1}}{b}
$$

where $\alpha$ is the angle of inclination of the straight line to the time axis.

Solving the characteristic equation (6) regarding $\mu_{1}$ gives, according to equation (7), the diffusion constant $D$. On the basis of the experimental data, the diffusion constant at temperatures of $20-25^{\circ} \mathrm{C}$ is $1.55-2.67 \cdot 10^{-10} \mathrm{~m}^{2} / \mathrm{s}$. For particles of average size of $5 \mathrm{~mm}, B i>1$, which demonstrates the insignificant affect of hydrodynamic conditions upon AG isolation rate.

These data on mass transfer were used to calculate the AG extraction process from larch wood particles in similar hydrodynamic conditions. The value of the diffusion constant $D$ was used to calculate the processes conducted at a given temperature. 


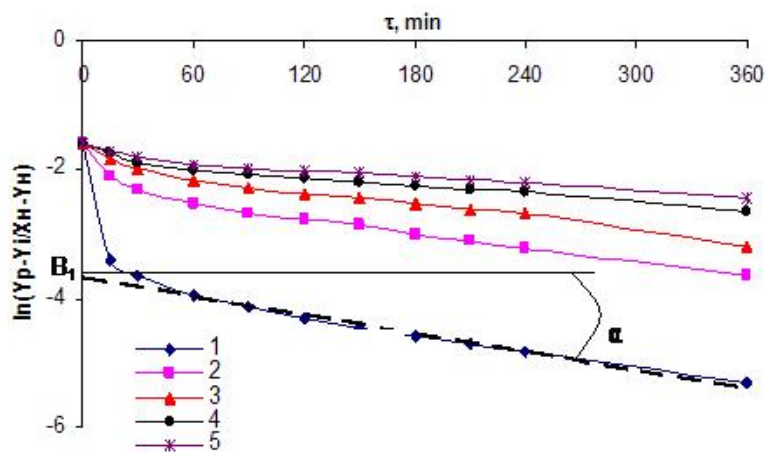

Figure 4. Graph of regular mode of AG extraction. Particle sizes, mm: 1 - 0.056; 2 - 0.86; 3 - 2.61; 4 - 3.24; $5-5.37$

Based on the experimental data, a mathematical model was developed, material balance was calculated, and the optimal parameters of the extraction process were determined [75]. The model was used to optimize the technological process and production algorithm.

According to the method developed, firstly DHQ and other phenolic extractive substances were isolated from larch wood particles by organic solvent, and then were exposed to extraction by circulating water at $60-80^{\circ} \mathrm{C}$ for $2-3 \mathrm{~h}$. The extract obtained was treated with a cationic flocculant solution to remove mechanical and colloidal impurities. Decolourized extract was ready for being concentrated and further purified by ultrafiltration.

Concentrations of AG water extracts were decolourized by flocculation, which was achieved by ultrafiltration using UAM-150P cellulose acetate membranes (Russia) [76]. Filtration rate decreased with time due to an increase in solution concentrations, viscosities and sedimentation of high-molecular particles on the membrane surface. Initial productivity decreased as initial AG solution concentration increased. However, initial productivity increased with increasing pressure gradient. At the final stage of ultrafiltration, when the process rate approaches a constant level, the higher the pressure gradient the lower the productivity, due to the higher rate of concentration at high pressure during equal time intervals.

Studies have been made of the influence of pressure upon the ultrafiltration process. The maximum degree of concentration is reached at the pressure gradient $\Delta \mathrm{P}=0.4 \mathrm{MPa}$. However, the optimal ratio between productivity and degree of concentration is at $\Delta \mathrm{P}=0.2 \mathrm{MPa}$.

Ultrafiltration results in simultaneous concentration of AG extracts and their purification by almost entirely filtering out low-molecular phenolic impurities. Purification efficiency depends on composition of the extract, membrane characteristics and conditions of filtration as well as a degree of concentration.

According to the IR spectroscopy and HPLC data, filtrate contains, together with phenolic substances, an oligomeric fraction of AG. Atomic absorption and X-ray fluorescence 
analyses have shown that ultrafiltration purifies AG from metal cations [76]. The total content of dry substances in filtrates is not more than $1-2.5 \%$.

To increase productivity of the ultrafiltration module, we also tested the UAM-500P membrane (Russia). Ultrafiltration dynamics of decolourized AG extracts have shown that filtration rate is in an inverse ratio to initial extract concentration. The use of a macroporous membrane allows ultrafiltration without pre-treatment of AG extracts by a flocculating agent. It has been proven experimentally that productivity of this process is comparable to that of extract decolourized by flocculation. Thus, for the UAM-500P membrane, pore blocking at the initial stage is not a limiting factor, unlike the case for UAM-150P. The optimal conditions of ultrafiltration have been determined to make the technology profitable.

After ultrafiltration, the concentrate was dried in a drying unit. The known methods of dry product isolation, by precipitation in alcohol or acetone [6], are disadvantageous for industrial use from a technological, economical and ecological point of view. The filtrate, without additional treatment, was mixed with fresh water and reused for DHQ extraction.

The method proposed, as compared to known methods, enables the following improvements:

- AG extraction from larch wood is realized after the isolation of DHQ and resin substances, giving a rather high purity of the extract

- the process is simple, energy-efficient and economically viable

- no expensive sorbents are needed and no toxic or combustible organic solvents are involved

- concentrates of dry substance content of up to $40 \%$ can be produced

- the closed water cycle allows water consumption and the amount of waste water to be decreased.

Additional AG purification from high-molecular phenolic impurities was realized by treatment of the water extracts with ecologically harmless oxidant (hydrogen peroxide) [17]. The optimal conditions were found to oxidize impurities without affecting the polysaccharide macromolecule.

For final product isolation from the concentrate, spray drying, lyophilic drying or fluid bed drying can be used.

The experiments showed that spray drying is technically and economically optimal. In a manufacturing pilot, different modes of AG spray drying were tested by varying the starting concentration of AG solution, air temperature at the drier input, air temperature at the drier output and pressure of compressed air at spraying. The temperature of the drying gas (air) was the most technologically relevant. The required humidity of the final product (less than $7 \%$ ) was reached at an air temperature higher than $100{ }^{\circ} \mathrm{C}$. The optimal process conditions produced AG of high quality. 
On the basis of our study, a technological scheme for isolating high purity AG was developed, involving:

1. Flocculation of AG solution (FR)

2. Oxidation of impurities in the AG solution (OR)

3. Microfiltration of the AG solution (MF)

4. Concentration of the AG solution by ultrafiltration (UF)

5. Spray drying of the concentrate (SD).

The manufacturing pilot revealed drawbacks to the proposed scheme: low productivity and high time consumption per product unit. Thus, the scheme was optimized.

The most reasonable sequence of steps was determined using a decision tree [77-79] with limited operation sequence combinations: spray drying was always the last step and, thus, was excluded from the decision tree; microfiltration and oxidation always followed flocculation. The decision tree, taking into account the limitations mentioned, is shown in Figure 5 .

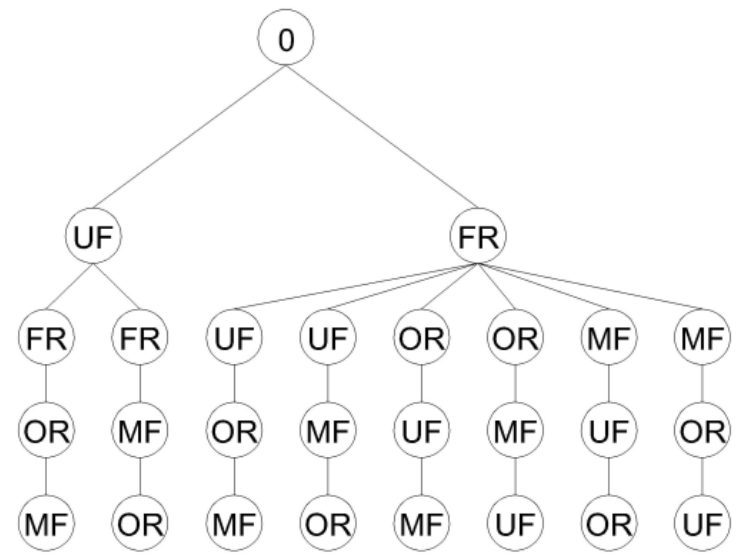

Figure 5. Decision tree

The variants were ranged from 1 to 7 according to these criteria:

- $\quad$ productivity

- material and reagent consumption

- $\quad$ steel intensity (investment)

- laboriousness (timetable)

- manufacturability.

The optimal variant is UF-FR-OR-MF (see Table 1), which has a four times higher productivity and a two times lower investment in comparison with the initial scheme.

An optimized technological scheme of arabinogalactan production was implemented at an experimental-industrial scale. 


\begin{tabular}{lcccccccc}
\hline & \multicolumn{7}{c}{ Possible algorithms } \\
\cline { 2 - 8 } Criteria & $\begin{array}{l}\text { FR-UF- FR-UF- FR-OR- FR-OR- } \\
\text { OR-MF }\end{array}$ & $\begin{array}{c}\text { FR- } \\
\text { MF-OR }\end{array}$ & $\begin{array}{c}\text { FR- } \\
\text { UF-MF }\end{array}$ & $\begin{array}{c}\text { MF-UF } \\
\text { MF- }\end{array}$ & $\begin{array}{c}\text { UF-FR- UF-FR- } \\
\text { UF-OR }\end{array}$ & $\begin{array}{c}\text { OR-UF } \\
\text { OR-MF MF-OR }\end{array}$ \\
\hline $\begin{array}{l}\text { Productivity } \\
\text { Material and }\end{array}$ & 1 & 1 & 1 & 1 & 1 & 1 & $\mathbf{7}$ & 7 \\
consumption & 3 & 3 & 3 & 3 & 3 & 3 & $\mathbf{1}$ & 1 \\
Steel intensity & 1 & 1 & 1 & 1 & 1 & 1 & 7 & 7 \\
Laboriousness & 3 & 5 & 3 & 5 & 7 & 7 & $\mathbf{2}$ & 1 \\
Manufacturability & 2 & 1 & 2 & 5 & 7 & 6 & $\mathbf{6}$ & 4 \\
Total & $\mathbf{1 0}$ & $\mathbf{1 1}$ & $\mathbf{1 0}$ & $\mathbf{1 5}$ & $\mathbf{1 9}$ & $\mathbf{1 8}$ & $\mathbf{2 3}$ & $\mathbf{2 0}$ \\
\hline
\end{tabular}

Table 1. Criteria of variant estimation

\section{Larch bark pectins}

\subsection{Physicochemical and biological properties of pectins}

Pectin substances are present in the majority of land and water plants, and in some freshwater algae [80]. Being an important component of cell walls, they are involved in ion exchange, water metabolism and cell wall structure formation. They stimulate seed germination and germ growth, provide turgor, etc.

The unique physicochemical properties of pectin make it indispensable in medical, food and cosmetic industries as a gelling agent, thickener, stabilizer and dietary fibre. Recently, it has become widely used as a matrix carrier for biologically active components in drugs. Pectins have physiological activities of their own (immunomodulating, hepatoprotective, anticarcinogenic, antimetastatic, etc.) making them applicable as medical preparations and biologically active food supplements.

Industrial demand for pectins in Russia is estimated at $2000 \mathrm{t} /$ year, of which $10 \%$ is for the fragrance and cosmetic industries, $15 \%$ goes to medicine and pharmaceuticals, and $75 \%$ is for the food industry [81]. However, this demand is generally met by imported production. There are recent innovative Russian developments that are ecologically harmless and economically viable (there is no need to utilize aggressive acid media and to support treatment facilities), therefore having a low cost price. The raw material for pectin is the marc of citrus fruit, apple, sugar beet and sunflower head pith. There are proposals for using other plants as raw materials, such as amaranth, small mallow, duckweed, silene, coffee beans, etc. [82-86].

The bark of L. sibirica Ledeb. and L. gmelinii (Rupr.) Rupr., having a $12 \%$ pectin content, is a promising alternative raw material. At our laboratory, we are conducting systematic studies of the structure and properties of pectin from these larch species to determine a suitable technology for its industrial production. 


\subsection{Isolation of pectin substances from larch bark}

There are a number of methods to isolate pectin polysaccharides from plant tissues, including hydrolysis extraction of dry raw material particles of certain sizes [87] using hot water, organic and inorganic acid solutions as well as salts, alkali or their mixtures as extracting solutions. Basic parameters of the pectin isolation process, such as raw material pre-processing, hydromodulus, temperature, extraction duration, medium $\mathrm{pH}$ and precipitator used, can all be varied depending on characteristics of the raw material [88]. We studied the influence of the following combinations of the basic parameters upon yield and product quality:

Experiment 1: 0.5\% ammonium oxalate solution (hydromodulus 1:5)

Experiment 2: $0.5 \%$ oxalic acid solution (1:5)

Experiment 3: equimolar mixture of $0.5 \%$ oxalic acid and $0.5 \%$ ammonium oxalate solutions (1:5)

Experiment 4: $0.25 \%$ sodium hydroxide solution (1:5)

Experiment 5: similar to experiment 3 (1:7)

Experiment 6: similar to experiment 3 (1:10)

In all the experiments, extraction process were the same $\left(\right.$ at $80{ }^{\circ} \mathrm{C}$ for $2 \mathrm{~h}$ of constant stirring).

The pectin samples obtained were white or light cream-coloured powders, tasteless and with no smell (Figure 6).

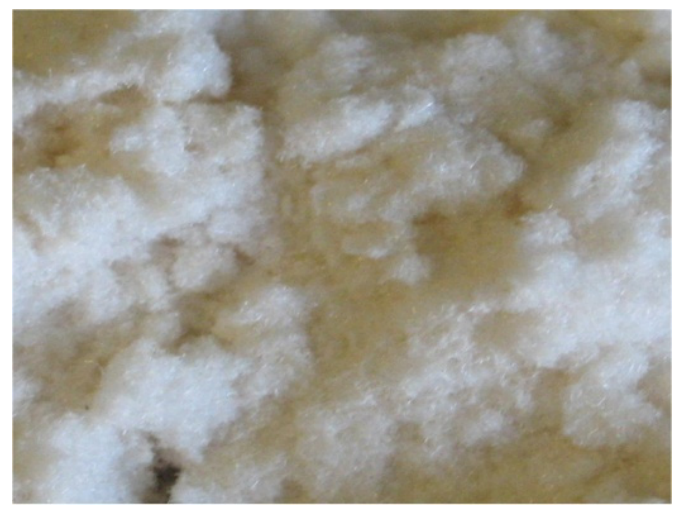

Figure 6. A laboratory sample of larch bark PS

Table 2 sets out the yield (\% of weight of absolutely dry bark, a.d.b.) and composition data of pectin substances obtained in experiments 1-6.

The highest yields were observed with a weak alkali solution, but the ash content was too high (16.66\%), which affected gelling ability [89]. The lowest ash content was found in the preparations isolated using an equimolar mixture of ammonium oxalate and oxalic acid (5$5.6 \%)$. 


\begin{tabular}{cccccc}
\hline \multirow{2}{*}{ Experiment } & $\begin{array}{c}\text { Yield, } \\
\text { \% of a.d.b. }\end{array}$ & Medium pH & \multicolumn{3}{c}{ Composition, \% } \\
\cline { 4 - 6 } & & 6.95 & 30.28 & 6.66 & Ash \\
\hline 1 & 0.77 & 1.90 & 31.17 & 5.75 & 8.89 \\
2 & 0.97 & 3.90 & 32.05 & 5.42 & 5.58 \\
3 & 1.64 & 11.97 & 36.55 & 4.51 & 16.66 \\
4 & 5.81 & 2.86 & 34.24 & 6.30 & 5.20 \\
5 & 2.71 & 2.84 & 31.48 & 6.82 & 5.08 \\
6 & 2.93 &
\end{tabular}

Table 2. Yield and elemental composition of pectin substances in larch bark

The optimal hydromodulus was observed in experiments 1-4 (hydromodulus 1:5) with yield increasing by 1.5 times. Hydromodulus provides insufficient penetration of extracting agent, lower than 1: 5. A 1:10 rise of hydromodulus (experiment 6) had no essential effect upon the yield and qualities of the product. Thus, the equimolar mixture of ammonium oxalate and oxalic acid used as an extracting solution at hydromodulus 1:7 (experiment 5) was the most effective in isolating pectin substances from larch bark, leading to a $2.7 \%$ yield of absolutely dry bark mass with ash content of $5.2 \%$.

Raw material pre-processing by solvents of increasing polarity (hexane, ethyl acetate and water) resulted in both enzyme deactivation and elimination of the impurities, therefore increasing the extracting solution's ability to access the plant cell walls. Notably, the preextracted substances are valuable for medicine [90] and the leather industry [91].

We experimentally compared the yields of pectins isolated with and without raw material pre-processing in the conditions described above (see Figure 7). It was shown that prior elimination of impurities leads to higher yield of the product (about 1.5 times), clearly due to higher availability of pectin substances.

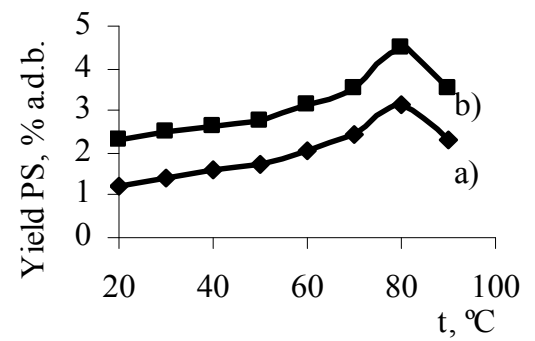

Figure 7. PS yield dependence on: a) raw material pre-processing, and b) extraction temperature

The PS yield increased as the extraction temperature rose, reaching a maximum at $80{ }^{\circ} \mathrm{C}$. The data obtained were in good correspondence with the literature on classic pectin isolation [89]: raising temperature causes partial hydrolysis of protopectin. Thus, pectin yield increases while at temperatures higher than $80{ }^{\circ} \mathrm{C}$ the superstructure of pectin substances is broken. This is also confirmed by the dependence of the molecular weights of the resulting pectins on extraction temperatures (see Figure 8.). 
Kinetic studies, particularly those concerning the pectin hydrolysis extraction process, have a particular interest. Pectin yields vs. extraction times are charted in Figure 9. A major part of PS is transferred into the extract within $1 \mathrm{~h}$ of extraction, after which there is no significant increase of yield.

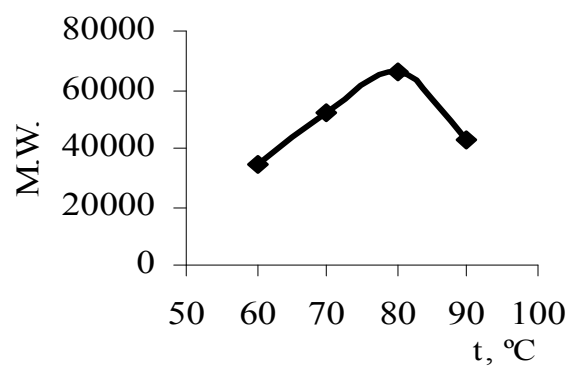

Figure 8. PS molecular weight (M.W.) dependence on extraction temperature

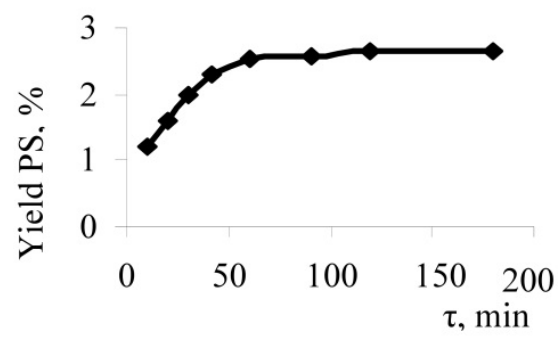

Figure 9. Dependence of PS yield on extraction time

We also studied the influence of type of precipitator used upon the yield and qualities of the product. For this purpose, pectin extract was prepared from larch bark by treating it with an equimolar mixture of $0.5 \%$ ammonium oxalate and $0.5 \%$ oxalic acid (hydromodulus $1: 7$ ) at $80{ }^{\circ} \mathrm{C}$ for $2 \mathrm{~h}$. The extract was concentrated in a circulation vacuum evaporator until it reached one third of its original volume. One half of the concentrate was precipitated with acetone and the other half with ethanol. Precipitators were added in equal quantity, dropwise while continuous stirring was applied. The precipitate was vacuum-filtered, dissolved in $100 \mathrm{ml}$ of distilled water by heating to $40-50{ }^{\circ} \mathrm{C}$ when necessary, and then again precipitated and filtered. The final precipitates were washed with the same precipitator and then with diethyl ether, dried in the air and then in a drier at $50{ }^{\circ} \mathrm{C}$, cooled to room temperature in a desiccator and measured to determine yield. It is noteworthy that the dropwise addition of precipitator into the extract increased yield by $0.5 \%$ compared to the usual precipitation procedure. We established that acetone is less selective, and ethanol therefore gives a purer product. Purity of the pectin preparation obtained can also be estimated based on galacturonic acid content [92]: for larch bark pectins precipitated by acetone and ethanol, the result was 69.77 and $78.12 \%$, respectively. 
Thus, the optimal procedure for isolating pectin substances from larch bark involves pretreatment by hexane, ethyl acetate and water, extraction by an equimolar mixture of $0.5 \%$ oxalic acid and ammonium oxalate solutions at hydromodulus 1:7 and an extraction temperature of $80{ }^{\circ} \mathrm{C}$ for $1 \mathrm{~h}$, and precipitation by ethanol. The method has been patented [93] and used for preparing the samples for physicochemical and application studies.

\subsection{Characterization of pectin substances}

Pectinase enzyme hydrolysis of PS samples isolated from larch bark by the above method, and further analysis of hydrolysis products by paper chromatography (PC), have shown an essential destruction of PS with formation of free D-galacturonic acid.

Table 3 sets out the main maxima of absorption bands in the IR spectra of PS and their assignment, proving the PS pectin nature of the samples [94].

\begin{tabular}{cc}
\hline Frequency $\left(v, \mathrm{~cm}^{-1}\right)$ & Assignment \\
\hline 3460 & $v(\mathrm{OH}), v\left(\mathrm{H}_{2} \mathrm{O}\right)$ \\
3260 & $v(\mathrm{NH})$ \\
2962,2872 & $v\left(\mathrm{CH}_{3}\right)$ \\
2573 & $v(\mathrm{OH})$, \\
1730 & $v(\mathrm{C}=\mathrm{O})$ в $\mathrm{COOH}$ \\
1640 & $\delta(\mathrm{OH})$ ᄉ \\
1540 & $\delta(\mathrm{NH})$ \\
$1380-1450$ & $\delta\left(\mathrm{C}-\mathrm{CH}_{3}\right), v(\mathrm{C}-\mathrm{O})$ pyranose rings \\
1331 & $\delta(\mathrm{OH})$ in pyranose rings \\
1265 & $v(\mathrm{C}-\mathrm{O})$ in esters \\
1150 & $v(\mathrm{C}-\mathrm{O}-\mathrm{C})$ \\
1095 & $v(\mathrm{C}-\mathrm{C})$ \\
1027 & $v(\mathrm{C}-\mathrm{OH})$ \\
890 & $\delta(\mathrm{C} 1-\mathrm{H})$ in glucopyranose ring \\
$766,629,528$ & pulse vibrations of pyranose ring \\
\hline
\end{tabular}

Table 3. Absorption band maxima in IR spectra of PS and their assignments

Thus, enzyme hydrolysis and IR spectroscopy data prove that the polysaccharide isolated from larch bark refers to the pectin group.

The monosaccharide composition of PS was determined by total acid hydrolysis with trifluoroacetic acid (TFA). Monosaccharide identification of PS was performed using gasliquid chromatography (GLC) and the sample was shown to consist of galacturonic acid, protein compounds and monosaccharides of arabinose, galactose, rhamnose, glucose, mannose and (in minor quantities) xylose. Dominant monosaccharides were galactose and arabinose, in a ratio of $2.7: 1$. 
The degree of homogeneity for PS was determined by ion exchange chromatography on DEAE cellulose with sodium chloride aqueous solutions. Four fractions were detected (Table 4). In the fractions PS-1 and PS-2, arabinose and galactose were predominant $(18.26 / 52.96 \%$ and $11.65 / 30.83 \%$, respectively); thus, they refer to acidic arabinogalactans. The acidic nature of PS was developed with D-galacturonic acid residues with the PS-1 proportion five times less than in PS-2, while in PS-3 and PS-4 it was a major monosaccharide, and thus they refer to pectins. The content of neutral monosaccharides in PS-4 was minimal compared to other fractions ( $3 \%$ mass). All the fractions contained protein compounds that were not eliminated by gel filtration. It seems likely that the protein and polysaccharide compounds were strongly aggregated, or that their molecular weights were close to each other.

\begin{tabular}{|c|c|c|c|c|c|c|c|c|c|}
\hline \multirow{3}{*}{ Sample* } & \multirow{3}{*}{ Yield, \% } & \multicolumn{8}{|c|}{ Content, \% } \\
\hline & & \multirow{2}{*}{ GalpA } & \multirow{2}{*}{ Protein } & \multicolumn{6}{|c|}{ Monosaccharides } \\
\hline & & & & Rha & Ara & Xyl & Man & Glu & Gal \\
\hline PS-1 & 12.1 & 5.67 & 6.9 & traces & 18.26 & 1.54 & 2.53 & 5.95 & 52.92 \\
\hline PS-2 & 5.9 & 29.12 & 7.3 & 0.53 & 11.65 & 1.02 & 2.71 & 8.81 & 30.83 \\
\hline PS-3 & 17.0 & 65.93 & 5.7 & 1.91 & 4.45 & 0.75 & 1.18 & 1.12 & 9.42 \\
\hline PS-4 & 37.0 & 79.87 & 3.6 & 0.35 & 0.93 & 0.18 & 0.24 & 0.21 & 1.06 \\
\hline
\end{tabular}

* PS-1 isolated with use of $0.01 \mathrm{M} \mathrm{NaCl}$ solution, PS-2 - $0.1 \mathrm{M} \mathrm{NaCl}$ solution, PS-3 and PS- $4-0.2 \mathrm{M} \mathrm{NaCl}$ solution

Table 4. Chemical characterization of PS sample after DEAE-cellulose fractioning

The amino acid composition of PS proteins was studied. The major components of PS were glutamic acid $(6 \%)$ and aspartic acid $(2.8 \%)$, while total content of amino acids with aliphatic side chains (glycine, alanine, valine, isoleucine, leucine) was 9\% (Figure 10).

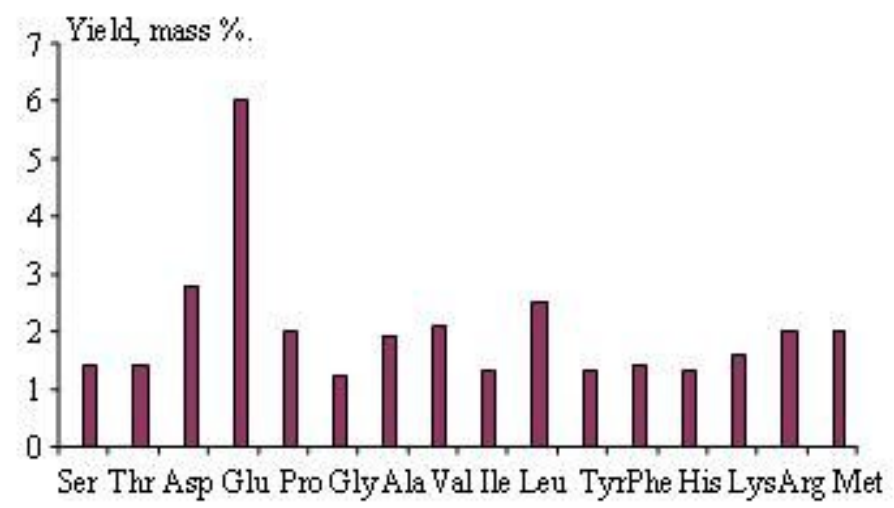

Figure 10. Amino acid composition of PS proteins 
Thus, we isolated PS from the bark of L. sibirica Ledeb. and L. gmelini (Rupr.) Rupr., pretreated with ethyl acetate and hot water. Enzyme hydrolysis with pectinase and IR spectroscopy were employed to prove the presence of pectin polysaccharides in the samples isolated. DEAE-cellulose chromatography revealed that PS includes four fractions, two of which are acidic arabinogalactans and the other two belong to the pectin group.

\subsection{Structural study of main chain of larch bark pectin}

Acid hydrolysis of PS by 2M TFA results in galacturonan PVG-1. The high value and positive sign of the rotation angle of $\left.+245.3^{\circ}(c) .1, \mathrm{H}_{2} \mathrm{O}\right)$ suggest $\alpha$-D-configuration of Dgalactopyranosyluronic acid residues.

Values of chemical shifts (CS) of carbon atoms in the ${ }^{13} \mathrm{C}$ NMR spectrum of PVG-1 (Table 5), compared to other data, [95] corresponded to those for carbon atoms in D-galacturonic acid residues in pyranose form which compose the linear fragment of pectin molecules (pectin core). The presence of an anomeric carbon atom signal at $101.9 \mathrm{ppm}$ indicated both $(1 \rightarrow 4)$ bonding between D-galacturonic acid residues and $\alpha$-configuration of C- 1 anomeric atoms. Signals at $176.2 \mathrm{ppm}$ were assigned to the C-6 atom and indicated a free carboxyl group in D-galacturonic acid residue. Additionally, there were galacturonic acid residues esterified by methoxyl in the PVG-1 molecule, according to signals with CS at $172.2 \mathrm{ppm}(\underline{\mathrm{C}}-6-\mathrm{OCH})$ and $54.4 \mathrm{ppm}\left(-\mathrm{O}_{\mathrm{CH}}\right)_{3}$. The ratio of the integrated signal intensity of carbon atoms observed in methoxyl and carboxyl groups suggests a high degree of galacturonan methoxylation. The ${ }^{13} \mathrm{C}$ NMR spectrum also showed signals at $\delta 76.1$ and 74.9 referring to the C-3 carbon atom substitute in $(\ldots \rightarrow 4)-\alpha$-D-GalpA- $(1 \rightarrow \ldots)$ galacturonic acid residue in the galacturonan molecule (the non-substituted atom has CS at $72.1 \mathrm{ppm}$ ).

\begin{tabular}{ccccccccc}
\hline Residue & $\mathrm{C}-1$ & $\mathrm{C}-2$ & $\mathrm{C}-3$ & $\mathrm{C}-4$ & $\mathrm{C}-5$ & $\mathrm{C}-6$ & $\begin{array}{c}\mathrm{C}-6- \\
\left(\mathrm{OCH}_{3}\right)\end{array}$ & $-\underline{\mathrm{CH}}_{3}$ \\
\hline $\begin{array}{c}\text { ( }) \text { - } \alpha \text {-D-Gal } \mathrm{pA}- \\
(1 \rightarrow\end{array}$ & 100.9 & 68.9 & $\begin{array}{l}76.1 \\
74.9\end{array}$ & 79.2 & 73.4 & 176.2 & 172.2 & 54.4 \\
\hline
\end{tabular}

Table 5. Chemical shifts of signals of galacturonic acid carbon atoms in ${ }^{13} \mathrm{C}$ NMR spectrum of PVG-1

Thus, according to spectral and chromatographic data, linear polysaccharide from larch bark has a structure of homogalacturonan consisting of $(\ldots \rightarrow 4)-\alpha$-D-GalpA-( $1 \rightarrow \ldots)$-linked fragments D-galacturonic acid has partially etherified by methoxyl groups with branching points at C-3 atom of galacturonopyranosyl residue.

\subsection{Structural study of side branches of larch bark pectin}

Partial acid hydrolysis of PS with 0.01M TFA for $3 \mathrm{~h}$ resulted in galacturonan PVG-2. According to ${ }^{13} \mathrm{C}$ NMR data, it was a pectin polysaccharide. The spectrum contained both typical signals of galacturonic acid residues, namely pronounced signals of anomeric carbon atoms at 100.4 and 104.4 ppm, and signals of carboxyl carbon atoms at 171.4, 166.5 and 53.7 
ppm, the latter two being signals of carbon atoms in uronic acid residues methoxylated by the C-2 and/or C-3 atoms (Table 6).. Intensities and spectral positions of signals at 68.9, $70.8,78.9$ and $72.2 \mathrm{ppm}$ corresponded to data in the literature for $\alpha$-D-GalpA residues connected by $1 \rightarrow 4$ bonds. There is a ratio of $1: 5$ between integral signal intensities of carboxyl and methoxyl carbon atoms, which suggests a high degree of PS methoxylation.

\begin{tabular}{|c|c|c|c|c|c|c|c|}
\hline Residue & $\mathrm{C} 1$ & $\mathrm{C} 2$ & C3 & $\mathrm{C} 4$ & C5 & C6 & $\begin{array}{l}-\mathrm{OCH}_{3} \\
\left(\underline{\mathrm{CH}}_{3-}\right)\end{array}$ \\
\hline$\rightarrow 4)-\alpha-\mathrm{D}-\mathrm{Gal}_{\mathrm{p}} \mathrm{A}-(1 \rightarrow$ & 100.4 & 68.9 & 70.8 & 78.9 & 72.2 & 171.4 & - \\
\hline $\begin{array}{l}\text { 2-MeO- } \alpha-\mathrm{D}-\mathrm{Gal}_{\mathrm{p}} \mathrm{A}- \\
(1 \rightarrow\end{array}$ & 100.9 & 166.5 & 69.6 & 78.9 & 73.8 & 171.4 & 53.7 \\
\hline $\begin{array}{l}\text { 3-MeO- } \alpha-\mathrm{D}-\mathrm{Gal}_{\mathrm{p}} \mathrm{A}- \\
(1 \rightarrow\end{array}$ & 100.9 & 68.9 & 166.5 & 78.9 & 73.8 & 171.4 & 53.7 \\
\hline$\beta$-D-Galp- $(1 \rightarrow$ & 104.64 & 71.7 & 74.1 & 69.6 & 76.1 & 62.0 & - \\
\hline$\rightarrow 6)-\beta-\mathrm{D}-\mathrm{Gal}_{\mathrm{p}}-(1 \rightarrow$ & 104.38 & 71.7 & 73.8 & 69.6 & 74.3 & 70.8 & - \\
\hline$\rightarrow 3,6)-\beta-\mathrm{D}-\mathrm{Gal}_{\mathrm{p}}-(1 \rightarrow$ & 104.64 & 71.7 & 82.5 & 69.57 & 74.1 & 71.4 & - \\
\hline$\alpha$-L-Araf- $(1 \rightarrow$ & 108.6 & 80.7 & 78.9 & 84.9 & 62.0 & - & - \\
\hline$\beta$-L-Arap- $(1 \rightarrow$ & 101.1 & 69.6 & - & - & - & - & - \\
\hline$\rightarrow 3,5)-\alpha$-L-Araf- $(1 \rightarrow$ & 108.6 & 80.7 & 84.9 & 83.2 & 67.8 & - & - \\
\hline$\rightarrow 2,5)-\alpha$-L-Araf- $(1 \rightarrow$ & 108.0 & 84.9 & 77.6 & 83.2 & 67.8 & - & - \\
\hline
\end{tabular}

Table 6. Chemical shifts in signals of carbon atoms in the ${ }^{13} \mathrm{C}$ NMR spectrum of PVG-2

In the ${ }^{13} \mathrm{C}$ NMR spectrum of PVG-2 samples there were upfield signals at 17.9 and 18.13 ppm belonging to C- 6 atoms in terminal rhamnose residues and in polysaccharide chains, respectively. The integral intensities of these signals and those of C-2 and/or C-3 and C-6 carbon atoms for galacturonan residues at 166.5 and $171.4 \mathrm{ppm}$ were found to have a ratio 1:5. The total integral intensity of signals for anomeric C-1 atoms for rhamnose and the total integral intensity of signals of anomeric atoms of galacturonan residues were equal to each other, i.e. they had the same ratio for rhamnose and galacturonan residue content in the chain. According to data in the literature, signals at $\delta 99.7,77.6,70.8,82.5,68.9$ and $17.9 \mathrm{ppm}$ are assigned to $\mathrm{C}-1, \mathrm{C}-2, \mathrm{C}-3, \mathrm{C}-4, \mathrm{C}-5$ and $\underline{\mathrm{CH}} 3$ carbon atoms in $\rightarrow 2,4)-\alpha$-L-Rhap- $(1 \rightarrow$ residues.

Thus, according to ${ }^{13} \mathrm{C}$ NMR spectral data, linear fragments of pectin polysaccharide isolated from larch bark are rhamnogalacturonans where D-galacturonic acid residues in pyranose form with an $\alpha$-configuration of their anomeric centre are connected 1-4 by glycosidic bonds. One fifth of galacturonan residues associated with the C-6 atom were esterified by methoxyl groups. The ratio between 2,4-substituted rhamnopyranosyl and galacturonosyl residues (1:5), thus, the main chain structure of the pectin polysaccharide was highly branched at the C-4 atoms of rhamnopyranosyl residues.

Further ${ }^{13} \mathrm{C}$ NMR spectrum analysis of the PVG-2 sample showed that arabinogalactan fragments are present in rhamnogalacturonan as side chains. Concerning signals of anomeric carbon atoms, the ${ }^{13} \mathrm{C}$ NMR spectrum of the PVG-2 sample showed that there are 
signals at 101.1, 104.38, 104.64 and $108.6 \mathrm{ppm}$, as well as signals of anomeric carbon atoms in galacturonopyranosyl residues of the galactan core. According to [9], intensities and values of CS can be assigned to signals of anomeric carbon atoms in $\beta$-L-Arap, $\alpha$-L-Araf and $\beta$-D$\mathrm{Gal}_{\mathrm{p}}$ residues. The most upfield of the signals mentioned ( $\left.\delta 101.1 \mathrm{ppm}\right)$ belong to terminal $\beta$ L-Arap residues. Signals at 104.38 and 104.64 ppm belong to C-1 in $\beta$-D-Galp residues while CS values of C-2, C-3, C-4, C-5 and C- 6 atom signals are calculated according to the official data for $\beta$-D-galactopyranosyl residues. Bonding at the C-3 and C-6 positions of $\beta$-Dgalactopyranose was proven by downfield shifts of these signals at 8.7 and 8.8-9.4 ppm, respectively, due to glycosylation of these atoms as compared to their positions in nonsubstituted $1 \rightarrow 3,6$ linked $\beta-D-G a l_{p}$ residues. Signals at $\delta 108.6 \mathrm{ppm}$, like those at 80.7, 78.9, 84.9 and $62.0 \mathrm{ppm}$, are terminal $\alpha$-L-arabinofuranose. The anomeric atoms of arabinose and galactose are monosaccharides integrated at a ratio of 1:2.

Hence, according to spectral data for the PVG-2 fragment of the pectin polysaccharide from larch bark, highly branched arabinogalactan was detected as side chains consisting of linear chains with $\rightarrow 3,6)-\beta-\mathrm{D}-\mathrm{Gal}_{\mathrm{p}}-(1 \rightarrow$ residues with branching at C-6 atoms. Side chains of arabinogalactan fragments contain terminal arabinose, both in pyranose and in furanose form, as well as $\rightarrow 2,5)$ - $\alpha$-L-Araf-( $(1 \rightarrow$ and $\rightarrow 3,5)-\alpha$-L-Araf-( $1 \rightarrow$ residues as intermediate fragments.

\subsection{Larch bark pectin peculiarities and implementation fields}

It has been determined that larch bark pectin substances possess immunomodulatory, antineoplastic, gastroprotective and antitoxic action [96-98]. In order to understand larch bark pectin's physiological and pharmacological action, we have started research focussed on examining its membrane-acting action. The vacuoles of isolated cell plants and their membranes were found to be an appropriate object for our research. The influence of pectin on membranes and the peculiarities of their barriers were estimated according to the change of destruction dynamics in isolated vacuoles in comparison with the control. The results are depicted in Figure 11. It has been established that implementation of pectin aqueous solutions leads to their protective action on vacuolar membranes, exceeding the control threefold. Thereby, the experiments proved that larch bark pectin possesses a membrane stabilizing activity.

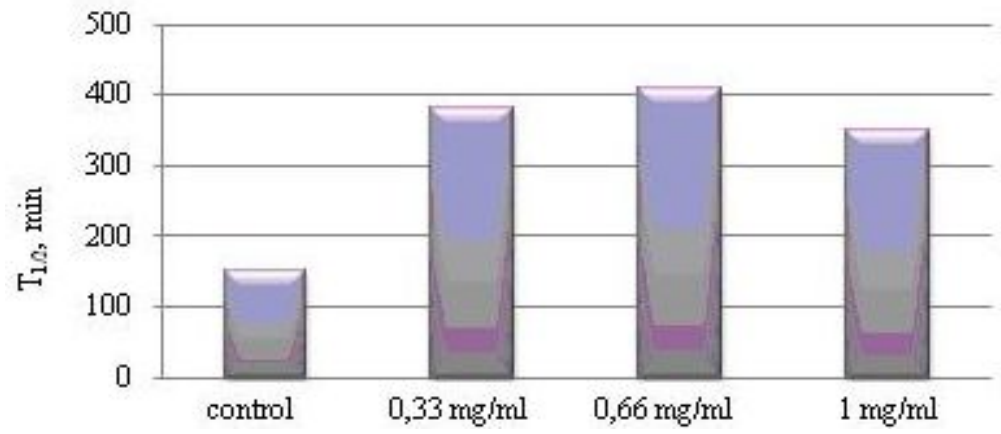

Figure 11. Influence of pectin upon isolated vacuole half-lives $\left(\mathrm{T}_{1 / 2}\right)$ 
In order to broaden larch bark pectin implementation fields, we carried out research into its implementation as a reducer and stabilizer of noble metal particles in nanosized state. Supramolecular structure peculiarities, optical activity, carboxyl and abundance of hydroxyl groups, and polymeric pectin molecule stabilizing effect provided significant potential in nanobiocomposite formation processes in metals with a polysaccharide matrix ("pectin metal (0)").

Synthesis of nanobiocomposites was carried out using the redox reactions of PS with silver nitrate. Nanobiocomposite samples 0.5 "pectin - $\operatorname{Ag}(0)$ " up to $72 \%$ content of silver were obtained in different reaction conditions. It was discovered that the effectiveness of the reaction to create a silver nanoparticle flow depends on medium spectrum $\mathrm{pH}$. The spectra of the mixtures of pectin and silver nitrate water solutions versus time reaction are depicted in Figure 12a. It was determined that, with a reduction of $\mathrm{pH}$ to 3.5, the $\mathrm{Ag}(\mathrm{I})$ reaction proceeds very slowly. This is demonstrated by the appearance of a link in the absorption spectrum in the range of $\lambda 280-470 \mathrm{~nm}$ only $24 \mathrm{~h}$ after the beginning of the reaction (Fig. 12a). The wide maximum low intensity link was indicated by the formation of silver metal primary centres. Despite this, the reaction speed of the reduction was so slow that even $96 \mathrm{~h}$ was not enough to create fully recovered $\operatorname{Ag}(0)$ centres. With pectin and $\mathrm{Ag}(\mathrm{I})$ interactions in reaction mixtures beginning at a $\mathrm{pH}$ of 7 , a symmetric bond at $\lambda_{\max } 420 \mathrm{~nm}$ can be observed in the electron spectra at the start of reaction by proving the formation of $\operatorname{Ag}(0)$ nanoparticles (Fig.12b, line 2). Even so, it takes about $24 \mathrm{~h}$ for the full silver cation conversion which was experimentally evaluated according to the absorption bond intensity growth. $\mathrm{Ag}(\mathrm{I})$ reduction with pectin at $\mathrm{pH}$ 11-12 proceeded swiftly immediately after mixing of the components (Figure 12b, line 4 and Figure 12c line 1) and finished within 30 min. Reduction under these conditions was also accompanied by variations in the particle size of $\operatorname{Ag}(0)$, as shown by the shift in the Plasmon pick position into the short-wave region at $10 \mathrm{~nm}$ (Figure 12c).

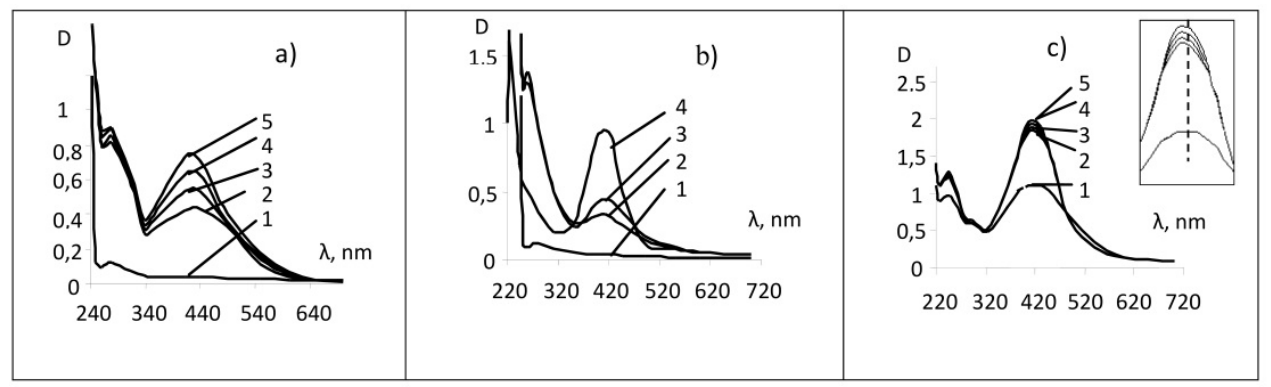

Figure 12. Absorption spectra of mixtures of aqueous solutions of pectin $(0.5 \%)$ and silver nitrate $(0.1 \%)$ in a ratio of 1:1 depending on: a) reaction duration: $1 \mathrm{~min}(1), 24 \mathrm{~h}(2), 48 \mathrm{~h}(3), 72 \mathrm{~h}(4), 96 \mathrm{~h}(5) ; \mathrm{b})$ medium pH: 3.5 (1), 7 (2), 9.7 (3), 11.5 (4); c) reaction duration at $\mathrm{pH}$ 11.5: $1 \mathrm{~min}(1), 30 \mathrm{~min}(2), 60 \mathrm{~min}$ (3), $180 \mathrm{~min}(4), 24 \mathrm{~h} \mathrm{(5)}$

Radiographic phase analysis of obtained nanobiocomposites of "pectin- $\operatorname{Ag}(0)$ " demonstrated it to be a mixture of radioamorphous and crystalline phases. There was a 
wide halo with maximum intensity at $\mathrm{d} \sim 0.46 \mathrm{~nm}$ in $2 \theta$ angle intervals from 8 to $60 \mathrm{E}$ (Figure13a) in a radioamorphous phase diffraction pattern typical of a pectin source. There were quite intensive but broadened lines typical of metallic silver (Figure 13b) during silver loading in the diffraction patterns of reaction products against a background of pectin reflection. The calculation of silver unit-cell parameters showed that in their quantity in the provided samples was lower than for massive silver and changed from 0.4036 to $0.4050 \mathrm{~nm}$ $(\forall 0.0008 \mathrm{~nm})$. Moreover, the average size of the coherent-scattering region (CSR) was calculated according to Selyakov-Sherarar's formula [99] to be in the range of $3 \mathrm{~nm}$. The data obtained demonstrated that, in the samples of $\mathrm{Ag}(0)$, the persistence of nanosized particles was stabilized by an amorphous phase with pectin.

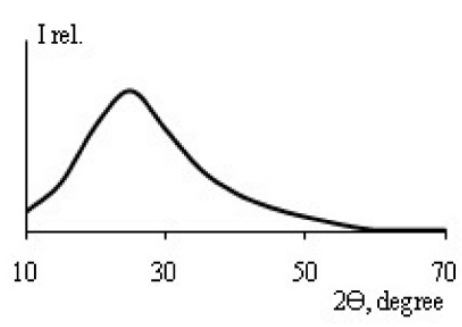

a)

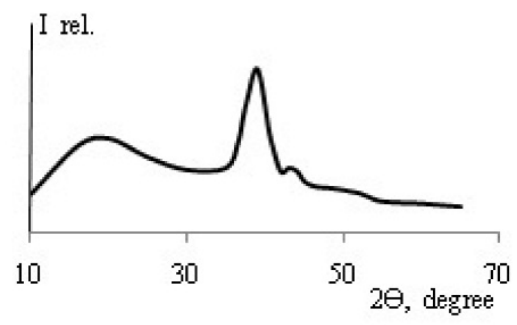

b)

Figure 13. Diffraction patterns of pectin sample (a) and of the "pectin- $\mathrm{Ag}(0)$ " nanobiocomposite sample (b)

"Pectin - Ag (0)" nanobiocomposite scanning electron microscopy (Figure 14) showed that the analysed samples contain particles considerably smaller than $100 \mu \mathrm{m}$.

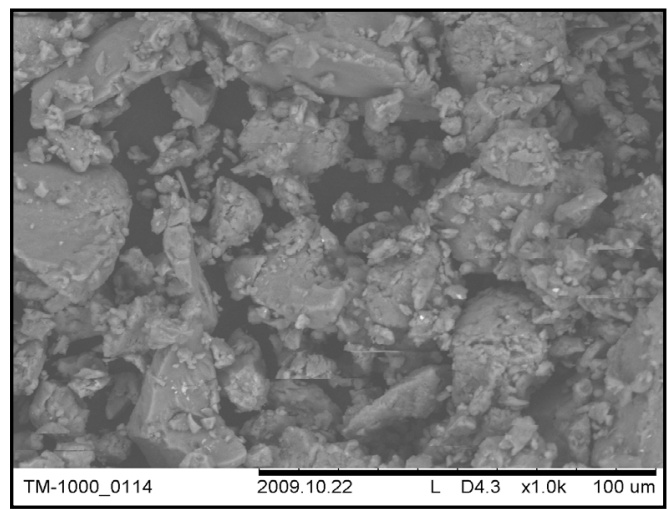

Figure 14. Electron microphotography of "pectin - $\mathrm{Ag}(0)$ " sample

Microphotography analysis of nanobiocomposites, obtained by the use of transmission electron microscopy, demonstrated that there are isolated silver particles of null valency in globular form (Figure 15a), of a size within the range from 4 to $17 \mathrm{~nm}$ (predominance (up to $80 \%)$ at $6-7 \mathrm{~nm}$, Figure $15 \mathrm{~b}$ ). 


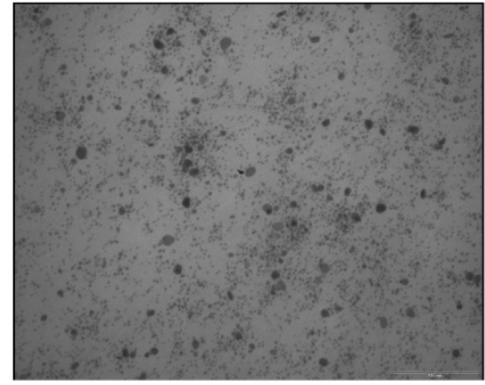

a)

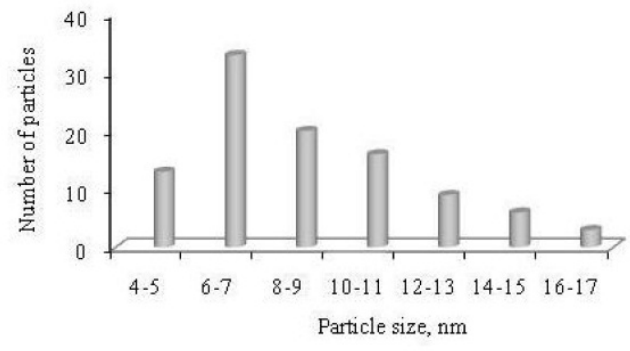

b)

Figure 15. Transmission electron microphotography, a), and size distribution graph of "pectin-Ag(0)" nanobiocomposite sample, b)

Thereby, "pectin-Ag(0)" nanobiocomposite formation takes place as a result of the interaction of pectin water solutions with $\mathrm{Ag}(\mathrm{I})$. Process speed increases significantly with variation within the alkaline $\mathrm{pH}$ range of the medium. The initial component proportion influences the results of the reaction: the more $\mathrm{Ag}(\mathrm{I})$ that falls per $1 \mathrm{~g}$ of pectin, the less the quantity of $\operatorname{Ag}(0)$ particles that is created in a nanosized condition. Using pectin implements reduction and stabilizing functions, and also adjusts the sizes of obtained $\operatorname{Ag}(0)$ nanoparticles.

\section{Cellolignin residue of larch wood as raw material for crystalline glucose production}

The cellolignin residue is formed during the chemical processing of larch wood using the technology for obtaining dihydroquercetin and arabinogalactan [100]. CR represents larch wood chips initially extracted by ethyl acetate and hot water. The larch wood chip basically consists of cellulose, hemicellulose, and lignin. The polysaccharide content in larch wood chips is $65-75 \%$ of the mass of its absolutely dry wood (a.d.w.) [101], and the content of water-soluble substances is $10-16 \%$ (in some samples up to $30 \%$ ) [102]. The content of holocellulose in CR (without water-soluble substances) is about $54 \%$ of its a.d.w. weight, whereas the content of holocellulose in the original larch wood is about $40 \%$ of its a.d.w. (also without water-soluble substances). The gain in the relative content of polysaccharides per mass of a.d.w. is about $13 \%$, which permits one to consider the CR as a polysaccharide"enriched" raw material from which it is possible to obtain sugar and other products by hydrolysis. Hemicellulose polysaccharides in the CR of larch wood are mainly represented by the water-soluble polysaccharide arabinogalactan and 4-O-methylglucuronoaraboxylans and galactoglucomannans [103], which are associated to differing degrees with cellulose. The yield of arabinogalactan from larch wood using dihydroquercetin production technology in which it is isolated as a by-product (without special optimization) accounts for $67 \%$ of its total content in the original raw material; therefore, the content of watersoluble substances in CR remains rather high, at $8.9 \%$. 
The data on the group composition of the components of CR were reported in [104]. The acid hydrolysis of hemicelluloses results in the formation of mono- and oligosaccharides, the presence of which substantially impairs the quality of hydrolysates and hinders the crystallization of glucose from these syrups. Therefore, it is necessary to purify CR from hemicelluloses. Hemicelluloses are commonly removed (to a particular limit) from the raw material, either by hot water extraction or by hydrolysis with diluted acid at elevated temperature.

In experiments with water hydrolysis of larch wood chips in laboratory autoclaves, the parameters of hydrolysis, i.e., temperature, hydromodulus, duration and the number of hydrolysis steps, were varied. The maximum total yield of water-soluble substances $(18 \%)$ was attained based on four-step hydrolysis. However, it is economically more attractive to perform one-step hydrolysis, with the conditions specified for obtaining a maximum yield of sugars with this hydrolysis method being as follows: a gradual increase in temperature from $25^{\circ} \mathrm{C}$ for $1 \mathrm{~h}$ and $160{ }^{\circ} \mathrm{C}$ for $1 \mathrm{~h}$ with a hydromodulus of $1: 6$. The yield of substances was $15 \%$. As indicated by paper chromatography (PC) and thin layer chromatography (TLC), the pre-hydrolysate contained arabinose, galactose, xylose, mannose and trace amounts of glucose [105].

Mild hydrolysis of hemicelluloses of CR was performed using 1-5\% sulphuric or hydrochloric acids at the boiling temperature of the solution $\left(100-105{ }^{\circ} \mathrm{C}\right)$. By choosing the optimal hydrolysis conditions, a maximum yield of reducing substances (RS) in hydrolysate, $1.1 \%$, was achieved with the use of $5 \%$ sulphuric acid, which corresponded to a $23 \%$ content of hemicelluloses or noncellulose polysaccharides in CR. The hexose content in the prehydrolysate was $33.9 \%$ of total sugars, as determined from the content of RS, and that of pentoses was $62.1 \%$; arabinose, galactose, xylose, mannose, and glucose were identified qualitatively. Significantly less amounts of polysaccharides were hydrolyzed with the use of $2 \%$ hydrochloric acid under the same hydrolysis conditions $-9.6 \%$.

Aqueous and acidic sugar solutions obtained during the pre-hydrolysis of CR (technological sugar solutions) contained greater amounts of fermentable sugars compared to other conifers and can be used in the production of feed for animals [106, 107] and other products.

To obtain pure glucose syrups, two alternative variants of acid hydrolysis of cellulose were considered: hydrolysis of CR and of cellulose itself after delignification of CR. Using the first variant, we studied the hydrolysis of CR by diluted (1.0-5.0\%) hydrochloric acid at high temperatures $\left(160-170{ }^{\circ} \mathrm{C}\right)$ and by concentrated $(50-85 \%)$ sulphuric acid at room temperature to compare the crystallization properties of glucose syrups obtained by the two methods. A high temperature hydrolysis of the raw material by diluted acid was carried out in laboratory autoclaves in four steps. As the acid concentration was increased from 1 to $5 \%$, a gain in the sugar content of the hydrolysates was observed. Thus, the mass portion of RS relative to the mass of a.d.w. during hydrolysis of sawdust was $5.4 \%$ using $1 \% \mathrm{H}_{2} \mathrm{SO}_{4}, 7.9 \%$ with $2 \% \mathrm{H}_{2} \mathrm{SO}_{4}, 9.2 \%$ with $3 \% \mathrm{H}_{2} \mathrm{SO}_{4}$, and $11.6 \%$ with $5 \% \mathrm{H}_{2} \mathrm{SO}_{4}$. However, simultaneously to an increase in the acid concentration, the quality of the hydrolysate was markedly impaired; an intensive dark colour appeared due to the formation of sugar degradation 
products, and the content of colloidal impurities in syrups at later stages caused severe problems. Conversely, the low temperature hydrolysis of CR (of the same raw material) by concentrated sulphuric acid made it possible to obtain a high yield of sugar in hydrolysates with a minimum content of degradation products. The maximum yield of RS was $64 \%$ using $70 \%$ sulphuric acid at the hydromodulus (1:5) and a hydrolysis time of $5 \mathrm{~h}$, and $62.6 \%$ using $80 \%$ sulphuric acid at the hydromodulus (1:5) and hydrolysis time of $2 \mathrm{~h}$. Hydrolysates contained no pentoses. These characteristics meet the requirements imposed upon hydrolysates from which crystalline glucose is isolated.

Thus, the use of concentrated sulphuric acid in the concentration range of $65-80 \%$ makes it possible to obtain hydrolysates with a maximum content of RS (up to 64\%) [108]. After additional hydrolysis (the inversion stage), the hydrolysate has a $\mathrm{pH}$ value close to 2 . On further evaporation of this hydrolysate, the acid is concentrated, which leads to further degradation of sugar; as a result, the yield of glucose decreases, and the syrup is contaminated with stained products.

Sulphuric acid was neutralized using barium acetate, sodium hydroxide and calcium hydroxide, and the contribution of each compound to formation of the mineral ash component in syrups was determined. The lowest ash content in the hydrolysate $(0.2 \%)$ was achieved by applying barium acetate. However, because of the toxicity of barium and its salts, the use of barium was abandoned. Upon neutralization of sulphuric acid by calcium hydroxide the ash content in the hydrolysate was initially as high as $10 \%$; nevertheless, preference was given to this compound alone since it is nontoxic, readily available, and convenient in operation. According to the "Glucose, crystalline hydrated" GOST 97588 Regulations [109], the ash content in the final product must not exceed $0.06-0.07 \%$, calculated for dry substance; therefore, it was necessary to provide neutralization conditions to decrease the ash content in hydrolysates. For neutralizing sulphuric acid, $\mathrm{pH}$ value was brought to $4-4.5$ at a temperature no higher than $80{ }^{\circ} \mathrm{C}$. The amount of calcium hydroxide was calculated according to the sulphuric acid neutralization reaction so as to exclude the over-alkalization of the solution [110]. The resulting dihydrate gypsum crystals were filtered off. The ash content in hydrolysate decreased by up to $0.5 \%$. In addition to glucose and mineral contaminations, the hydrolysate contained, dependent on hydrolysis conditions, the products of partial hydrolysis of the lignocarbohydrate complex of wood-mono-, di-, tri-, and oligosaccharides-as well as impurities belonging to different classes of organic compounds: acid-soluble lignin, furfurol, oxymethylfurfurol, a lignohumic complex, colloids, levulinic acid, and other organic acids [106]. At the next stage, we assessed the nature of substances by determining the colour of hydrolysates and selected how to remove them from sugar solutions [111]. It was possible to assign some impurities, that by their nature are associated with lignin, to substances based on their colouring. First of all, this was acid-soluble lignin. According to the published data, 2-3\% of total lignins are dissolved in the hydrolysis of coniferous wood by a solution of $72 \%$ sulphuric acid [103].

In addition, coloured substances are formed during sugar degradation: hexosans form high molecular weight substances of brown colour, which partially precipitate from solution, and pentosans form furfurol, which imparts a yellow colour to hydrolysate. Under acidic 
conditions, lignin and sugar degradation products, i.e., furfurol and oxymethylfurfurol, form condensed products in small amounts, and insoluble humic compounds; and the products of incomplete hydrolysis of polysaccharides, oligosaccharides, can be partially adsorbed by acid-insoluble lignin [106]. Hydrolysates were clarified using activated carbon BAU (Russia). The UV spectrum of a neutralisate from CR shows an absorption band at 280 $\mathrm{nm}$, which disappears after treatment of the neutralisate by activated carbon. Treating the hydrolysate with dichloroethane followed by IR analysis of the concentrated extract made it possible to identify it as acid-soluble lignin. Thus, the treatment of hydrolysates with activated carbon significantly reduces the content of acid-soluble lignin in hydrolysates (from 1.4 to $0.3 \%$ ).

The scheme of the acid-hydrolytic transformation of cellulose to glucose with preliminary delignification of lignocellulose raw material by industrial methods [112] is the second variant, which also makes it possible to obtain high purity glucose syrups. Its main advantage is that it enables glucose syrups to be obtained with a factor of merit of no less than $85 \%$, which are not contaminated with colouring impurities of ligno-carbohydrate origin and ash components. It is known that, during the low temperature hydrolysis of cellulose by concentrated acids, partial destruction of cellulose with the formation of watersoluble products occurs [113]. Under optimized conditions, concentrated sulphuric acid almost completely dissolves cellulose, and the cleavage of glycoside bonds proceeds in a homogeneous medium. As a result of hydrolysis, a mixture of products differing by the polymerization degree (PD) is formed: from comparatively high molecular weight cellulose and cellodextrins (PD from 7 to 50-60) to oligosaccharides (mainly di- and trisaccharides) and glucose. The composition of the mixture and the ratio of the products in the hydrolysate depend on the hydrolysis conditions. These products also vary in water solubility. Thus, cellodextrins, oligosaccharides, cellobioses and monosaccharides are water-soluble, and part of the cellulose itself, mainly its crystalline moiety, and hydrocellulose do not dissolve in water.

Thus, the hydrolysis of cellulose enables firstly the isolatation of intermediate water-soluble hydrolysis products with simultaneous removal of sulphuric acid without its chemical neutralization, which in turns prevents the entry of mineral impurities into syrups; and, secondly, obtaining of the required monomeric sugar, i.e., glucose, in one stage, by subsequent additional hydrolysis of the intermediate product. The hydrolysis of industrial cellulose was carried out by $72 \%$ sulphuric acid at room temperature for $1 \mathrm{~h}$ with regular stirring of the hydrolysate mass; in this case, cellulose had completely dissolved within the first $15 \mathrm{~min}$. Increasing the hydrolysis duration up to 2 and $3 \mathrm{~h}$ did not significantly affect the final yield of the product, which was $80-90 \%$ of the weight of absolutely dry cellulose (a.d.c.) [114].

We arbitrarily called this product the inverted polysaccharide (IPS) since this name reflects its position in the technological scheme. Dried IPS is a white or pale cream powder. The product is partially soluble in water (the insoluble fraction accounts for $43 \%$ of the weight of IPS), is soluble in aqueous alkaline solutions, and exhibits a lower PD than the starting cellulose (150; PD for starting cellulose, 573). The content of cellulose in an aqueous IPS solution was estimated, using HPLC, to be $2 \%$ of the a.d.c. A comparative analysis of IR 
spectra of the starting cellulose and IPS indicated that IPS is cellulose with a high degree of amorphism [94]. In particular, this is evidenced by strong changes in the IR spectrum of IPS in the region of 600-1500 $\mathrm{cm}^{-1}$, which accompanies changes in the polysaccharide hypomolecular structure, and smoothing of the intensity of so-called crystallinity bands at $1100,1140,1190,1250,1360$, and $1420 \mathrm{~cm}^{-1}$ [115]. The IR spectrum of the product contained no absorption bands at 1112 and $1162 \mathrm{~cm}^{-1}$, which are typical of the spectra of a highly ordered cellulose structure. The residual sulphuric acid content in an aqueous IPS solution was $0.2 \%$, indicating that $98 \%$ of the acid taken for hydrolysis is removed simultaneously with the isolation of IPS (without chemical neutralization).

In order to convert IPS to the monomeric form of sugar (glucose), an inversion was carried out at high temperature using a diluted acid. We studied the kinetics of the IPS inversion using diluted (0.075-1.5\%) hydrochloric acid [116]. The choice of this acid was primarily dictated by the fact that sodium chloride formed during the neutralization of the acid by $\mathrm{NaOH}$ is a part of the complex composite (CC) of glucose with the formula $\left(\mathrm{C}_{6} \mathrm{H}_{12} \mathrm{O}_{6}\right)_{2} \cdot \mathrm{NaCl} \cdot \mathrm{H}_{2} \mathrm{O}$, the decomposition of which results in the release of crystalline glucose. Considering that the potential yield of glucose, on inversion by $5 \%$ sulphuric acid at $100{ }^{\circ} \mathrm{C}$ for $5 \mathrm{~h}$, is $1.5 \%$ in the hydrolysate, which corresponds to a glucose yield equal to $82 \%$ of the weight of a.d.c., the acid concentration of $0.125 \%$ and temperature of $170{ }^{\circ} \mathrm{C}$ represent the optimum inversion conditions under which the yield of RS in the invertion is at its maximum; the time taken for attaining the maximum yield in these conditions is minimal. Thus, during the hydrolysis of cellulose and the subsequent inversion of IPS, the main glucose content in the inverted solution is about $70 \%$ of the mass of RS; i.e., the real yield of glucose is $35-45 \%$ of a.d.c.

It should be noted that these glucose syrups are transparent, of a light yellow colour, and are distinguished by a high factor of merit (85-90\% and more) (Figure 16). In comparison, the yield of glucose from CR (the first variant of hydrolysis) is $23-25 \%$. CG is isolated from glucose solutions either by direct or salt crystallization [117]. We studied the crystallization properties of glucose syrups obtained by hydrolysis of CR and cellulose using both the direct and salt methods. As mentioned above, the factor of merit of starting syrups must be no less than $85 \%$ for the successful crystallization of glucose using the direct method. Glucose syrups obtained by hydrolysis of cellulose completely meet this requirement. The application of activated carbon increased the quality of the syrup since direct crystallization occurred only in clarified syrups.

In order to perform direct crystallization, cellulose hydrolysis was used to obtain a hydrolysate with a RS content of $1 \%$, pH 4.4, and a factor of merit of $94 \%$, which was allowed to stand at room temperature for spontaneous crystallization. After two weeks, the onset of crystallization was visually observed. Crystallization by itself, without the creation of special temperature conditions, progresses slowly (taking a month and more). The method of salt crystallization of glucose has some advantages over direct crystallization. It does not require a deep purification of hydrolysates, the crystallization process is shorter and simpler (there is no need for a multiple recrystallization), and the yield of glucose increases. 


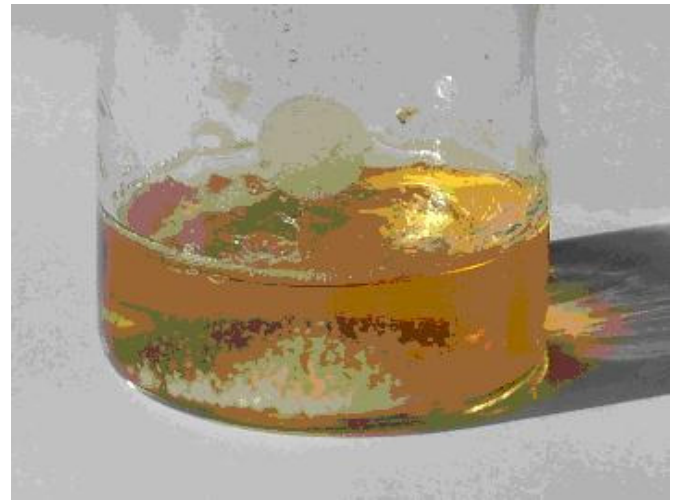

Figure 16. Glucose syrup from larch wood CR

We studied the crystallization conditions of glucose using its $\mathrm{CC}$ with sodium chloride $\left(\mathrm{C}_{6} \mathrm{H}_{12} \mathrm{O}_{6}\right)_{2} \cdot \mathrm{NaCl} \cdot \mathrm{H}_{2} \mathrm{O}$ and examined $\mathrm{CC}$ crystals obtained from model mixtures of glucose, sodium chloride and water, as well as from experimental glucose syrups obtained by the hydrolysis of CR and cellulose [118].

The crystallization of $\mathrm{CC}$ was studied using artificial mixtures in which the $\mathrm{NaCl}$ content varied from $15 \%$ to a twofold excess relative to the glucose content. In all cases, a crystalline phase formed. The composition of the crystalline phase was determined by elemental analysis. We determined that the range of $\mathrm{NaCl}$ :glucose ratios from 0.2:1 to 0.7:1 (parts by weight) is optimal for the formation of CC. Similarly, we determined the crystallization conditions for CC in hydrolysates of $\mathrm{CR}$ and cellulose. CC crystals were isolated from hydrolysates; the artificial mixtures were colourless and transparent and had well-defined facets. According to the chemical analysis data, they have a composition close to being stoichiometric: $\mathrm{C}-32.5 \%, \mathrm{H}-5.9 \%$ and $\mathrm{Cl}-9.7 \%$. Theoretically, $\mathrm{CC}$ with the general formula $\left(\mathrm{C}_{6} \mathrm{H}_{12} \mathrm{O}_{6}\right)_{2} \cdot \mathrm{NaCl} \cdot \mathrm{H}_{2} \mathrm{O}$ contains $\mathrm{C}-33 \%, \mathrm{H}-6 \%$, and $\mathrm{O}-18.13 \%$.

According to $\mathrm{X}$-ray phase analysis, $\mathrm{CC}$ monocrystals synthesized from pure solutions have the unit cell parameters $\mathrm{a}=\mathrm{b}=16.8, \mathrm{c}=17.0 \AA$ and $\beta=120^{\circ}$, and represent a hexagonal prism. Based on the symmetry of lauegrams and weissenbergograms, they belong to the diffraction class $\mathrm{P} \overline{3} \mathrm{~m}$ with regular extinctions at $1 \neq 3 \mathrm{n}$. Therefore, the spatial group of CC crystals was determined as $\mathrm{P}_{1} 12$ (151) and $\mathrm{P} 3_{2} 12$ (153).

The set of diffraction maxima obtained by X-ray phase analysis of CC crystals and the reference indicates that, under the experimental conditions used, glucose in the presence of sodium chloride crystallizes as $\mathrm{CC}$ with the formula $\left(\mathrm{C}_{6} \mathrm{H}_{12} \mathrm{O}_{6}\right)_{2} \cdot \mathrm{NaCl} \cdot \mathrm{H}_{2} \mathrm{O}$.

Thus, when studying the crystallization properties of glucose syrups produced by acid hydrolysis of the crystalline glucose of larch wood, we obtained CC glucose crystals with sodium chloride, upon decomposition of which D-glucose is released in crystalline form. In addition, glucose can be directly crystallized from glucose syrups produced by the hydrolysis of cellulose with a high factor of merit (more than $85 \%$ ). 
The ways in which the efficiency of hydrolysis of polysaccharides from wood CR can be increased are of a great interest. One method is the steam explosion hydrolysis of cellulose containing raw material, which makes possible the efficient and completely ecologically safe decomposition of lignocellulose material into its constituents: lignin, hemicellulose, and cellulose.

We studied the steam explosion hydrolysis of CR from larch wood, and showed that this method can be used for effective prehydrolysis processing of larch wood CR [119].

Hence, a laboratory scheme has been developed which will be used as the technological basis for obtaining crystalline glucose from the CR in larch wood [120].

\section{Experimental section}

Arabinogalactan was extracted using technology from L. sibirica Ledeb. [76] at the experimental-industrial plant and purified with methods described in [73, 17]. Molecular masses of arabinogalactan were defined with a high-performance liquid chromatography (HPLC) method, assisted by the Agilent Technologies 1260 Infinity chromatographic system using $0.1 \mathrm{M}$ sample solutions of $\mathrm{LiNO}_{3}$ on PL aquagel-OH- $40.8 \mathrm{~mm}, 300 \times 7.5 \mathrm{~mm}$ column, with a PL aquagel-OH Guard $8 \mathrm{~mm} 50 \times 7.5 \mathrm{~mm}$ precolumn, standardized according to dextrans with 25, 12 and $5 \mathrm{kDa}$ molecular mass standard solutions and monosaccharides.

IR spectra were registered in $\mathrm{KBr}$ tablets on a "Specord 75IR" spectrophotometer with a 500$4000 \mathrm{~cm}^{-1}$ interval. UV spectra were registered with a "Specord UV-vis" spectrophotometer (10 mm layer thickness). NMR ${ }^{13} \mathrm{C}$ spectra of AG samples were registered with a "Varian VXR 500S" spectrometer with a $125.1 \mathrm{~Hz}$ operating frequency; $\mathrm{D}_{2} \mathrm{O}$ was used as solvent. Deuteroaceton was used as an internal standard. The correlation of galactose and arabinose chains, composed of AG macromolecules, were calculated according to the correlation between integral intensities of carbon galactose anomeral atomic signals and arabinose. The ratio of galactose to arabinose units in AG macromolecules was calculated from the ratio of the intensities of signals from anomeric carbon atoms of glactose and arabinose [10].

Pectin polysaccharides (PS) were extracted from the bark of L. sibirica Ledeb. and from $L$. gmelini (Rupr.) Rupr. according to the scheme depicted in Figure 17. Larch air-dried bark (500 g), which was initially ground and treated with ethyl acetate, was extracted using distilled water at $70{ }^{\circ} \mathrm{C}$ over $3 \mathrm{~h}$. Raw material residue was poured with a mixture $(1: 1, \mathrm{v} / \mathrm{v})$ $0.5 \%$ of ammonium oxalate water solution and $0.5 \%$ oxalic acid water solution and heated at $80{ }^{\circ} \mathrm{C}$ for $2 \mathrm{~h}$. The extract was concentrated. Polysaccharides were precipitated with a triple volume of ethyl alcohol or acetone and dried with lyophilization. As a result, we obtained PS. The PS was dissolved in water and aminoacids were detected on AAA339M automatic analyser.

PS (50 mg) was dissolved in $20 \mathrm{ml}$ of water. Pektinaza (2 mg; Sigma, USA) water solution was added. The mixture was temperature-controlled at $37{ }^{\circ} \mathrm{C}$ for $3 \mathrm{~h}$. Then, a reaction mixture was heated for $5 \mathrm{~min}$ in a water bath at $100{ }^{\circ} \mathrm{C}$. Coagulated protein was separated by centrifugation. The obtained supernatant was concentrated and up to $5 \mathrm{ml} 96 \%$ ethyl 
alcohol was added (4 volumes). Deposition was separated with centrifugation. Alcoholic supernatant was concentrated and analysed with the help of PC.

Galacturonic acid content in PS was defined according to the reaction with 3,5-dimethyl phenol in the presence of concentrated $\mathrm{H}_{2} \mathrm{SO}_{4}$, protein using the Lowry method [121] and based on the calibrating schedule for a bovine serum albumin 80000 Da. Paper chromatography was carried out on "Filtrak FN-13" paper with a descending method in a nbutanol-pyridine-water system (volume correlations 6:4:3, respectively). To define carbohydrates, aniline phthalate was poured on the paper and heated at $105{ }^{\circ} \mathrm{C}$. Gas-liquid chromatography was carried out using a Hewlett-Packard 4890A (USA) chromatograph equipped with a flame-ionization detector, RTX-1 $(0.25 \mathrm{~mm} \times 30 \mathrm{~m})$ capillary column, argon carrier gas, and 1:60 dumping. Temperature rate: $175^{\circ} \mathrm{C}(1 \mathrm{~min})-250^{\circ} \mathrm{C}(2 \mathrm{~min}), \Delta 3 \% \mathrm{~min}$.

A full acid hydrolysis PS (5 mg) was carried out for the implementation of $2 \mathrm{M}$ trifluoroacetic acid $(2 \mathrm{ml})$ which contained myo-inositol $(1 \mathrm{mg} / \mathrm{ml})$. The mixture was heated in a soldered ampoule for $5 \mathrm{~h}$ at $100{ }^{\circ} \mathrm{C}$, and the acid was removed with a repeated dry evaporation with added methanol. As a result, we obtained PVG-1.

Ion-exchange chromatography PS (100 mg) was carried out on a DEAE-cellulose $(25 \times 2 \mathrm{~cm})$ column. $\mathrm{NaCl}$ solutions were used as an eluent with increasing concentrations $(0.01 \mathrm{M}-1 \mathrm{M}$, $60 \mathrm{ml} / \mathrm{h}$ elution speed, fractions selection by $12 \mathrm{ml}$ ). Pick correspondent fractions at the output bents were combined, dialysed and lyophilized. As a result, we obtained PS 1-4 fractions. The monosaccharide composition of each fraction was defined with GLC in acetate polyol after preliminary hydrolysis.

In order to obtain acetate polyol, each PS 1-4 fraction was dissolved in a 1M ammonia solution $(1 \mathrm{ml})$ and $5 \mathrm{mg}$ of $\mathrm{NaBH}_{4}$ was added. The mixture was kept for one day at a room temperature. Then, $\mathrm{NaBH}_{4}$ was eliminated by adding 2-3 drops of concentrated acetic acid; $0.2 \mathrm{ml}$ of dry pyridine and acetic anhydride were added to the dry residue. The mixture was acetilized at $100{ }^{\circ} \mathrm{C}$ for $1 \mathrm{~h}$. The solution was dry-evaporated until pyridine and acetic anhydride were removed, first by adding $1 \mathrm{ml}$ of toluene and then $1 \mathrm{ml}$ of methanol. The obtained acetate mixture of PS 1-4 polyol fractions was dissolved in $0.2 \mathrm{ml}$ of dry chloroform and moved quantitatively to Appendorf tubes, concentrated up to $0.1-0.2 \mathrm{ml}$ and analysed with the GLC method.

PS (5 mg) partial acidic hydrolysis was carried out using 0.01M TFA ( $2 \mathrm{ml})$, which contained myo-inositol $(1 \mathrm{mg} / \mathrm{ml})$. The mixture was heated in a soldered ampoule at $100{ }^{\circ} \mathrm{C}$ for $3 \mathrm{~h}$. The acid was removed using a repeated dry evaporation with added methanol. As a result, we obtained PVG-2.

After extraction of dihydroquercetin, arabinogalactan and resin, the larch chip presented as a cellolignin residue. The chip had the following dimensions: $25 \times 15 \times 5 \mathrm{~mm}$, and sawdust fraction, $1 \times 2 \times 2 \mathrm{~mm}$.

Bleached pulp from Baikal Pulp Mill was used for hydrolysis: polymerization degree 573, ash $1.1 \%$, humidity $3 \%$. Cellulose hydrolysis was carried out using $72 \%$ sulphuric acid and water in a ratio of $1: 3$ at room temperature for $1 \mathrm{~h}$. Hydrolysis products-inverted 
polysaccharides-were precipitated with a five-fold ethanol volume. The precipitate was filtered and washed with alcohol the last washed portion achieved a neutral reaction. The product was dried in the air at up to $6 \%$ humidity. Acid content of inverted polysaccharides was defined using $1 \mathrm{~N} \mathrm{HCl}$ titration. Inversion of IPS was carried out in $0.75-1.50 \%$ solutions, hydromodulus $1: 30$, at $100-170{ }^{\circ} \mathrm{C}$, for $0.25-3.0 \mathrm{~h}$ inversion duration. The potential content of reducing substances in hydrolyzates was defined by inversion of water-soluble polysaccharides with $5 \%$ sulphuric acid. $20 \% \mathrm{NaOH}$ was used to neutralize the hydrochloric acid. Glucose quantitative content in neutralisate $(\mathrm{pH} 4-5)$ was defined by HPLC methodology.

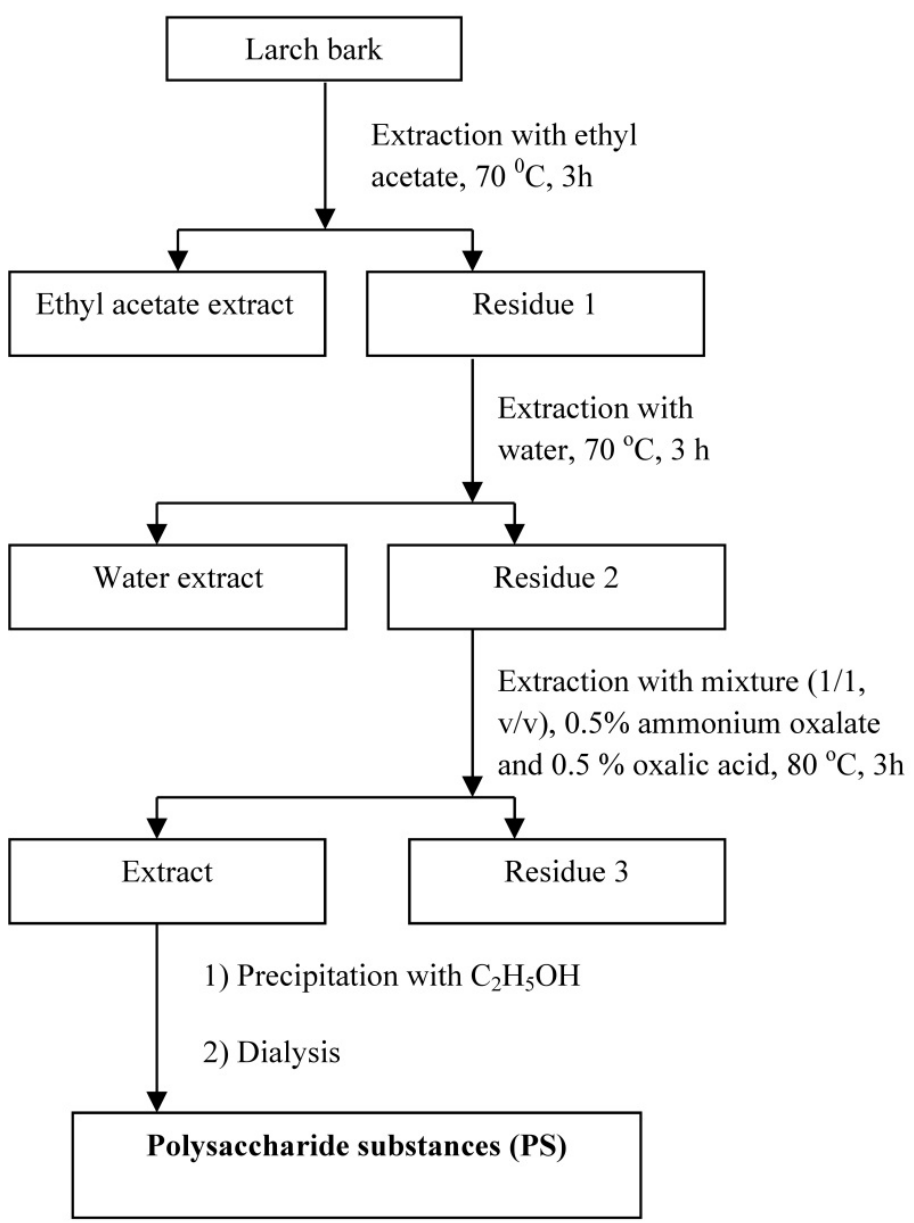

Figure 17. Extraction scheme of pectin substances from larch bark

Larch cellolignin timber residue with particles having dimensions of 25x15x5 mm was used for explosive autohydrolysis. Autoexplosive hydrolysis was carried out in a special $200 \mathrm{ml}$ 
capacity autoclave, which allowed us to conduct a quick decompression of the reactor (steam explosion). Hydrolysis conditions were: 200 and $220^{\circ} \mathrm{C}$, duration 2 and $5 \mathrm{~min}$.

The laboratory scheme for obtaining crystalline glucose is depicted in Figure 18.

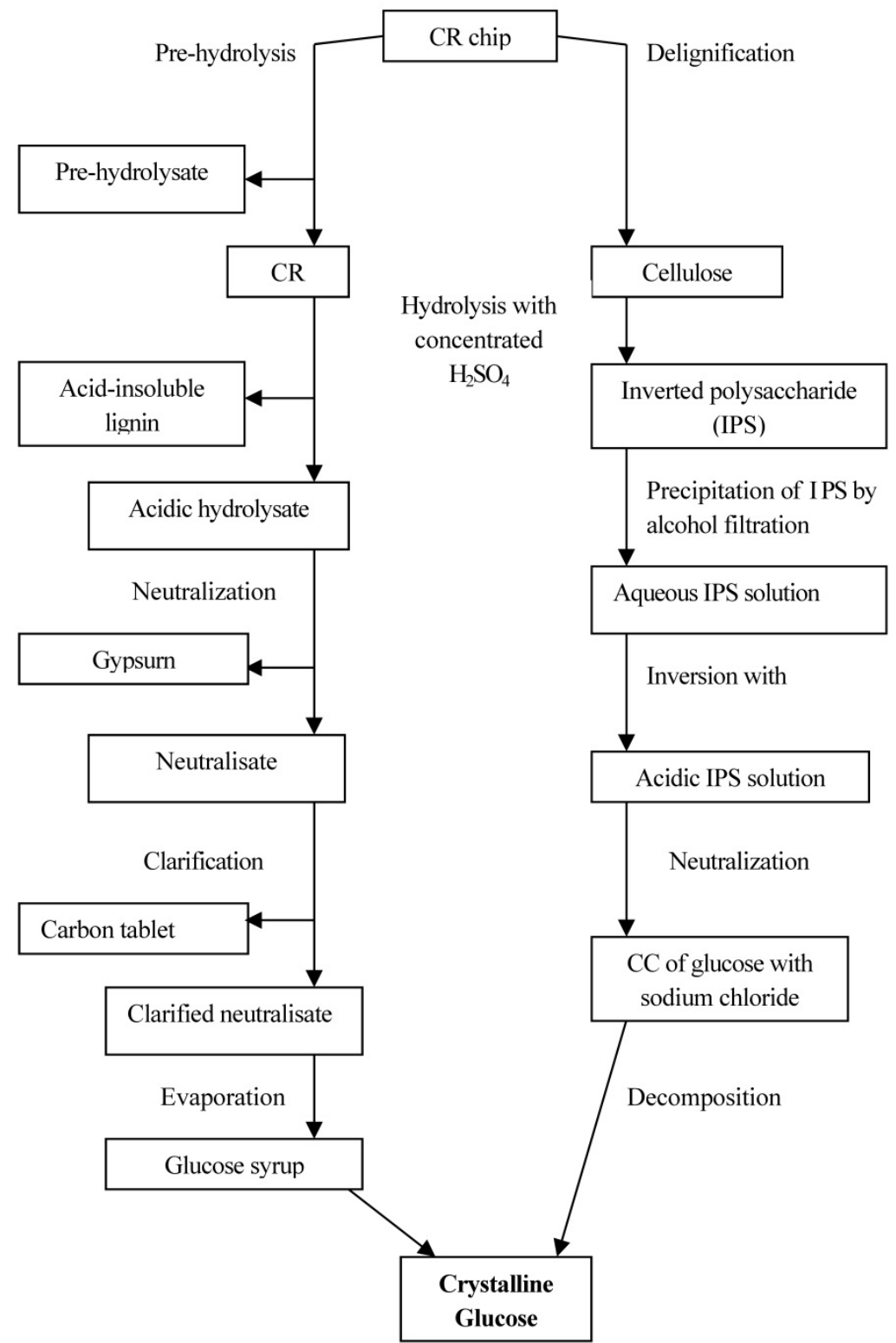

Figure 18. Laboratory scheme for obtaining crystalline glucose 


\section{Conclusion}

This chapter therefore summarizes studies on polysaccharides in the context of the development of technology for $100 \%$ processing of larch wood and bark as forestry waste in order to provide new medicines, veterinary drugs, dietary supplements and valuable materials for the cosmetics and agricultural industries. There are data on larch wood and bark extraction by the two-phase solvent system, namely the kinetic study of extraction processes, diffusion constants, mass-transfer coefficients, mechanisms and physicochemical characterization of the transfer process, its mathematical modelling and structural characteristics of the samples isolated. This work aims to support the development of economically and ecologically viable production technology for high-demand products on the basis of renewable raw materials with a $15-20 \%$ increase of forestry efficiency due to waste processing. The technology will provide new medicines and food supplements, as well as cheaper, by $40-50 \%$, analogues, to those currently known.

\section{Author details}

Natalya Nikolaevna Trofimova, Elena Nikolaevna Medvedeva, Nadezhda Viktorovna Ivanova, Yuriy Alekseevich Malkov and Vasiliy Anatolievich Babkin

Laboratory of Wood Chemistry, Federal Research Budget Institution, A.E. Favorsky Institute of Chemistry, Siberian Branch, Russian Academy of Sciences, Irkutsk, Russia

\section{Acknowledgement}

This project has been supported by a State Contract with the Department of Industry, Science and Technology of the Russian Federation №43.044.1.1.26.38(2002-2004); by a State Contract with the Agricultural Department of the Government of Irkutsk Oblast №02-66 (2010-2011); and by RAS and SB RAS Grants (2005-2012). The authors are grateful to all their colleagues at the Laboratory of Wood Chemistry of A.E. Favorsky Irkutsk Institute of Chemistry who have contributed to this project.

\section{References}

[1] Clarke A, Anderson R, Stone B (1979) Form and function of arabinogalactans and arabinogalactan-proteins. Phytochemistry. 18(4): 521-540.

[2] Antonova GF, Tukavkina NA (1983) Water soluble substances of larch and their possible applications. Khimia Drevesiny. 2: 89-96.

[3] Adams MF, Douglas C (1963) Arabinogalactan-a review of literature. TAPPI. 46: 544-548.

[4] Aspinall GO (1964) Some recent developments in the chemistry of arabinogalactans. In: Chimie et Biochimie de la Lignine, de la Cellulose et des Hemicelluloses. Grenoble: Actes du Symposium International de Grenoble. pp89-97.

[5] Medvedeva SA, Aleksandrova GP (2003) Modification strategy and biopotential of natural polysaccharide arabinogalactan. In: Panorama Sovremennoi Khimii Rossii [Polymer Synthesis and Modification]. Moscow: Khimia. pp328-356. 
[6] Medvedeva EN, Babkin VA, Ostroukhova LA (2011) Larch arabinogalactan: properties and application prospects. Khimia rastitel'nogo syr'ia. 1: 27-37.

[7] Chochieva MM, Tsvetayeva IP, Yurieva MK, Zaytseva AF (1958) Arabinogalactan distribution in the Dahurian larch wood. Works of the USSR AS Forest Institute. 45: 3149.

[8] Ponder G, Richards G (1997) Arabinogalactan from Western larch. Part III: Alkaline degradation revisited, with novel conclusions on molecular structure. Carbohydrate Polymers. 34: 251-261.

[9] Karacsonyi S, Kovacik V, Alfoldi J, Kubackova M (1984) Chemical and ${ }^{13} \mathrm{C}$ NMR studies of arabinogalactan from Larix sibirica L. Carbohydrate Research.134: 265-274.

[10] Medvedeva EN, Fedorova TE, Vanina AS, Rokhin AV, Es'kova LA, Babkin VA (2006) Arabinogalactan structure and properties vs. methods of its isolation from larch wood and purification techniques. Khimia rastitel'nogo syr'ia. 1: 25-32.

[11] Prescott J, Groman E, Gyongyi G (1997) New molecular weight forms of arabinogalactan from Larix occidentalis. Carbohydrate Research. 301: 89-93.

[12] Ovodov YS (1998) Polysaccharides of phanerogams: their structure and physiological activity (review article). Russian Journal of Bioorganic Chemistry (Bioorganicheskaya Khimiya). 24: 483-501.

[13] Arifkhodzhaev AO (2000) Galactans and galactan-containing polysaccharides of higher plants. Khimiya prirodnykh soedinenii. 3: 185-197.

[14] Groman E, Enriquez P, Jung Chu, Josephson L (1994) Arabinogalactan for hepatic drug delivery. Bioconjugate Chemistry. 5: 547-556.

[15] Grieshop CM, Flickinger EA, Fahey GC Jr (2002) Oral administration of arabinogalactan affects immune status and fecal microbial populations in dogs. The Journal of Nutrition. 132: 478-482.

[16] Robinson RR, Feirtag J, Slavin JL (2001) Effects of dietary arabinogalactan on gastrointestinal and blood parameters in healthy human subjects. Journal of the American College of Nutrition. 20: 279-285.

[17] Medvedeva EN, Babkin VA, Makarenko OA, Nikolaev SM, Khobrakova VB, Shulunova AM, Federova TE, Es'kova LA (2004) Preparation of high purity larch arabinogalactan and study of its immunomodulating properties. Khimiya rastitel'nogo syr'ia. 4: 17-23.

[18] Dubrovina VI, Medvedeva SA, Vityazeva SA, Kolesnikova OB, Aleksandrova GP, Gutsol LO, Grishenko LA, Chetverikova TD (2007) Structure and Immunomodulating Action of Arabinogalactan of Siberian Larch and its Metal Derivatives. Irkutsk: Asprint. $145 \mathrm{p}$.

[19] Robinson RR, Causey J, Slavin JL (2001) Nutritional benefits of larch arabinogalactan. In: McCleary BV, Prosky L. (eds.) Advanced Dietary Fiber Technology. Oxford: Blackwell Science Ltd. p443-451.

[20] Causey J, Robinson R, Feirtag J, Fulcher R, Slavin J (1999) Long term supplementation of arabinogalactan in humans and its effects on blood lipids, glucose and insulin. The FASEB Journal. Part I:3.

[21] Zarubaev VV, Ostrouhova LA, Medvedeva EN, Babkin VA, Kiselyov OI (2010) Antiviral preparations based on larch wood biologically active substances. Bulletin of Eastern-Siberian Science Centre SB RAMS. 1(71): 76-81. 
[22] European Patent Office. Arabinogalactan as Immune Enhancer, EP 2327411 A1, Bulletin 2011/22. European Patent Office; 2011.

[23] Lonza. Nutrition. http://www.lonza.com/products-services/nutrition.

[24] Gaines Nutrition. Ara-Plus (90 capsules) (Mfr: D'Adamo Personalized Nutrition/North American Pharmacal) (Professional quality product).

http://www.gaines.com/store/NorthAmerPharmacal/EM-ARAPLinfo.html (accessed Nov.1994).

[25] Kiselev OI, Babkin VA, Tikhonov VP (2010) Drug for Prophylaxis of Influenza and Upper Respiratory Tract Infections. RF Patent 2401117.

[26] Burke S, Scheuer C, Mullard K (2009) Ophthalmic compositions comprising a terpene and a natural polymer. WO 2009018060 (A1). European Patent Office. http://worldwide.espacenet.com/publicationDetails/biblio?FT=D\&date=20090205\&DB=EPO DOC\&locale $=r u \_R U \& C C=W O \& N R=2009018060 A 1 \& K C=A 1$. Accessed on April 2005.

[27] Jung C, Enriquez P, Palmacci S, Josephson L, Lewis JM (1995) Arabinogalactan derivatives and uses thereof. US Patent Number 5478576.

[28] Cui L, Faraj A, el Alaoui A (1997) Arabinogalactan (9kDa)-9- $\beta$-Darabinofuranosyladenine-5'-monophosphate, a novel liver-targeted conjugate that selectively inhibits hepatitis B virus replication in vitro. Antiviral Chemistry \& Chemotherapy. 8: 529-536.

[29] Josephson L, Rutkowski JV, Paul K, Frigo T, Korba BE, Tennant B, Groman EV (1996) Antiviral activity of a conjugate of adenine-9- $\beta$-D-arabinofuranoside - 5'- monophosphate and a $9 \mathrm{kDa}$ fragment of arabinogalactan. Antiviral Therapy. 1(3): 147-156.

[30] Groman EV, Menz ET, Enriquez PM, Jung C (1996) Delivery of Therapeutic Agents to Receptors using Polysaccharides. US Patent Number 5544386.

[31] Josephson L, Groman EV, Jung C, Lewis JM. (1994) Targeting of therapeutic agents using polysaccharides. US Patent Number 5336506.

[32] Nogawa M, Akaike T, Maruyama A (2001) Polyethylenimine/arabinogalactan conjugate as a hepatocyte specific gene carrier. S.T.P. Pharmaceutical Sciences. 11: 91-102.

[33] Ehrenfreund T, Golenser J, Frankenburg S, Domb AJ (2000) Water soluble amphotericin B - arabinogalactan conjugates for the treatment of experimental leishmaniasis. In: Proceedings of the $27^{\text {th }}$ International Symposium on the Controlled Release of Bioactive Materials, 7-13 July 2000, Porte Maillot, Paris, France. pp578-579.

[34] Ehrenfreund-Kleinman T, Azzam T, Falk R, Polacheck I, Golenser J, Domb AJ (2002) Synthesis and characterization of novel water soluble amphotericin B - arabinogalactan conjugates. Biomaterials. 23: 1327-1335.

[35] Pozharitskaya ON, Urakova IN, Shikov AN (2008) Solid Nanocomposition for Delivering Biologically Active Substances. WIPO Patent Application WO/2008/123798.

[36] Reis RL (2008) Natural-based Polymers for Biomedical Application. Cambridge: Woodhead. $802 \mathrm{p}$.

[37] Enriquez P, Jung C, Groman E (1996) Directed delivery of radioprotectants using a receptor - specific carrier. US Patent Number 5490991.

[38] Domb AA (2001) Biodegradable Polycation Composition for Delivery of an Anionic Macromolecule in Gene Therapy. PCT Int. Application WO 2001007486 A1. See URL http://www.patentstorm.us/patents/7001891.html. 
[39] Azzam T, Eliyahu H, Shapira L, Linial M, Barenholz Y, Domb AJ (2002) Polysaccharideoligoamine based conjugates for gene delivery. Journal of Medicinal Chemistry. 45: 1817-1824.

[40] Dutta RC (2007) Drug carriers in pharmaceutical design: promises and progress. Current Pharmaceutical Design. 13: 761-769.

[41] Jain A, Gupta Y, Jain SK (2007) Perspectives of biodegradable natural polysaccharides for site-specific drug delivery to the colon. Journal of Pharmacy and Pharmaceutical Sciences. 10: 86-128.

[42] Kochetkov NK (1967) Carbohydrate Chemistry Methods. Moscow: Mir. 512 p.

[43] Domb A, Benita S, Polachek I, Linden G (2000) Drug conjugates with oxidized arabinogalactan or dextran. US Patent Number 6011008.

[44] Ponedelkina IY, Saitgalina EA, Tolstikov GA, Dzemilev UM, Tolstikova TG, Odinokov VN, Lukina ES (2009) Modified arabinogalactans and a method for the production thereof. Patent RU 2359975, WO 2008/123799.

[45] Mudarisova RKh, Shirokova EN, Badykova LA, Borisov IM, Tolstikova TG, Sorokina IV, Dolgikh MP, Monakova YB (2005) Synthesis and pharmacological activity of the oxidized fractions of arabinogalactan from siberian larch (Larix sibirica L.). Pharmaceutical Chemistry Journal. 39: 418-421.

[46] Badykova LA, Mudarisova RKh, Tolstikova TG, Borisov IM, Monakov YuB (2005) Arabinogalactan poly- and oligosaccharides modified with 5-aminosalicylic acid. Chemistry of Natural Compounds. 41(3): 272-275.

[47] Badykova LA, Mudarisova RKh , Khamidullina GS, Aminev KhK, Borisov IM, Monakova YB (2006) Modification of arabinogalactan and its oxidized forms with $p$ aminosalicylic acid. Russian Journal of Applied Chemistry. 79: 1626-1628.

[48] Badykova LA (2007) Reaction of arabinogalactan from Siberian larch with 5aminosalicylic acid, 4-aminosalicylic acid and isonicotinic acid hydrazide. Abstract of candidate's PhD thesis. Ufa: Institution of the Russian Academy of Sciens Institute of Organic Chemistry of Ufa Scientific Centre of the Russian Academy of Sciences (IOChem USC RAS), Russia. 26 p.

[49] Medvedeva EN, Neverova NA, Fedorova TE, Babkin VA, Meteleva ES, Dushkin AV, Tolstikova TG, Khvostov MV, Dolgikh MP (2010) Structural transformations of arabinogalactan from the Siberian larch during mechanochemical processing and the biological properties of the products. Russian Journal of Bioorganic Chemistry. 36: 853-859.

[50] Tolstikova TG, Tolstikov GA, Dushkin AV, Meteleva ES (2008) Water Soluble Medical Composition and Synthetic Method Thereof. RU Patent 2337710.

[51] Dushkin AV, Meteleva ES, Tolstikova TG, Tolstikov GA, Polyakov NE, Neverova NA, Medvedeva EN, Babkin VA (2008) Mechanochemical preparation and pharmacological activity of water-soluble intermolecular complexes of arabinogalactan and pharmaceutical drugs. Russian Chemical Bulletin. 57: 1299-1307.

[52] Tolstikova TG, Khvostov MV, Bryzgalov AO, Dushkin AV, Tolstikov GA (2010) Plant polysaccharide arabinogalactan as new pharmacon clathrating agent. RAS Reports 433: 713-714.

[53] Babkin VA, Medvedeva EN, Neverova NA, Chipanina NN, Aksamentova TN, Meteleva ES, Dushkin AV (2009) Study of mechanocomposites on the basis of arabinogalactan and medical substances. In: Materials of the IV Russian Scientific Conference: New 
Achievements in Chemistry and Chemical Technology of Plant Raw Material. Barnaul. 21-23 April 2009. pp176-178.

[54] Medvedeva EN, Neverova NA, Ostroukhova LA, Babkin VA, Gus'kov SA, Meteleva ES, Dushkin AV (2010) Mechanical composites based on biologically active compounds from larch wood. Chemistry of Natural Compounds. 42: 1-4.

[55] Trofimov BA, Sukhov BG, Aleksandova GP, Medvedeva SA, Grishchenko LA, Mal'kina AG, Feoktistova LP, Sapozhnikov AN, Dubrovina VI, Martynovich EF, Tirskii VV, Semenov AL (2003) Nanocomposites with magnetic, optical, catalytic and biologically active properties based on arabinogalactan. Doklady Chemistry. 393(4): 287-288.

[56] Sukhov BG, Aleksandrova GP, Grishchenko LA, Feoktistova LP, Sapozhnikov AN, Proidakova OA, T'kov AV, Medvedeva SA, Trofimov BA (2007) Nanobiocomposites of noble metals based on arabinogalactan: preparation and properties. Journal of Structural Chemistry. 48(5): 922-927.

[57] Aleksandova GP, Grishchenko LA, Fadeeva TV, Medvedeva SA, Sukhov BG, Trofimov BA (2006) Antimicrobial Preparation. RU Patent 2278969.

[58] Ohr L (2001) Arabinogalactan Adds More than Health Benefits. Prepared Foods. 170: 55.

[59] Babkin VA, Medvedeva EN, Sambueva ZG, Khobrakova VB, Neverova NA, Suyuncheva BO, Tatsyi AA (2012) Medical and biological properties of bakery and pastry products enriched with larch arabinogalactan. Khimia rastitel'nogo syr'ia. 2: 185-193.

[60] Ermakova MF, Chistyakova AK, Shchukina LV, Pshenichnikova TA, Medvedeva EN, Neverova NA, Belovezhets LA, Babkin VA (2010) Effect of arabinogalactan isolated from Siberian Larch on the baking value of soft wheat flour and bread quality. Russian Journal of Bioorganic Chemistry. 36: 951-956.

[61] Neretina OV, Medvedeva EN, Babkin VA (2011) Production Technology of Prophylactic Bakery and Compositions of Prophylactic Biscuit, Cheese and Sugar Cookies. RU Patent 2430614.

[62] Nesteruk VV, Vershchako VA, Likhova NV, Babkin VA, Medvedeva EN (2011) Production Technology of Oatmeal Cookies Containing Prophylactic Arabinogalactan Supplement and Composition Thereof. Patent application 2011113945.

[63] Utochkina EA (2011) Study and technology development of arabinogalactan-enriched cultured milk product. Abstract of PhD thesis. Blagoveshchensk: Far Eastern State Agrarian University; Russia.

[64] Galochkin VA, Galochkina VP, Maksimenko SV (2008) Non-specific resistance and meat productivity in calves at arabinogalactan-enriched feeding. Sel'skokhozyaistvennaya biologia. 4: 89-95.

[65] Maksimenko SV (2008) Influence of arabinogalactan upon productivity and non-specific resistance of calves. Problemy biologii produktivnykh zhivotnykh. 1: 82-86.

[66] Torshkov AA, Fomichev YuP (2010) Application of arabinogalactan in raising broiler chickens. Orenburg Agrarian University Reports. 1: 172-175.

[67] Torshkov AA, Gerasimenko VV (2010) Changes in chemical composition of broiler chicken meat at the use of arabinogalactan. Orenburg Agrarian University Reports. 2: 167-169.

[68] Moskovtsev NG, Belova TP, Valetov TA (1988) Isolation of water extracted substances from larch wood. Khimiya Drevesiny (Wood Chemistry). 1: 112-116. 
[69] Kuznetsova SA, Kuznetsov BN, Aleksandrova NB, Danilov VG, Zhizhaev AM (2005) Obtaining arabinogalactan, dihydroquercetin and microcrystalline cellulose using mechanochemical activation. Chemistry for Sustainable Development. 13: 261-268.

[70] Kuznetsova SA, Mikhailov AG, Skvortsova GP, Aleksandrova NB, Lebedeva AB (2005) Intensifying the process of water extraction of arabinogalactan from larch wood. Khimia rastitel'nogo syr'ia. 1: 53-58.

[71] Antonova GF (1977) Study of fraction analysis of polysaccharide arabinogalactan from Siberian larch wood. Khimiya Drevesiny (Wood Chemistry). 4: 97-100.

[72] Medvedeva EN, Ostroukhova LA, Neverova NA, Onuchina NA, Babkin VA ( 2011) Phenolic admixtures in larch wood arabinogalactan. Khimiya rastitel'nogo syr'ia. 1: 45-48.

[73] Babkin VA, Kolzunova LG, Medvedeva EN, Malkov YuA, Ostroukhova LA (2005) Production method of arabinogalactan. RU Patent 2256668.

[74] Akselrud GA, Altshuler MA (1983) Introduction to Capillary-Chemical Technology. Moscow: Khimiya. 264 p.

[75] Malkov YuA, Ostroukhova LA, Babkin VA (2002) Application of mathematical modeling method for technology development of isolating extracted substances from larch wood. Khimiya rastitel'nogo syr'ia. 2: 133-138.

[76] Babkin VA, Malkov YuA, Medvedeva EN, Babkin DV, Ostroukhova LA, Kolzunova LG, Zolotar' RN, Nikolaev SM, Khobrakova VB (2005) Technology of arabinogalactan isolation from larch wood and research of its biological activity. In: Phytopharm 2005: proceedings of the Ninth International Congress, St. Peterburg. 22-25 June 2005. pp165-168.

[77] Kafarov VV, Vetokhin VN (1987) Fundamentals of Automatic Design of Chemical Production. Moscow: Nauka. 624 p.

[78] Mukhlenov IP (1986) Chemical-technological Systems. Leningrad: Khimiya. 425 p.

[79] Kafarov VV, Meshalkiin VP, Perov VL (1974) Principles of Mathematical Modeling of Chemical-technological Systems. Moscow: Khimiya. 624 p.

[80] Ovodov YuS, Golovchenko VV, Gunter EA, Kutchin AV (2009) Pectic Substances of Plants of the European North of Russia. Ekaterinburg: Uro RAN. 112 p.

[81] Tehnokonsalt Management. The organisation of production technology of pectin (in Russian). http://www.tc-m.ru/index.php/155.html. Accessed 2004 March.

[82] Minzanova ST, Mironov VF, Sosnina NA, Vyshtakalyuk AB, Lapin AA, Smolentsev AV, Mironova LG, Khirug SS, Konovalov AI (2007) Technological aspects of the manufacturing of amaranth fodder additives. Doklady Chemistry. 413(1): 75-78.

[83] Bubenchikov VN, Drozdova IL, Kochkarov VI (2002) Method of Isolation of the Polysaccharides Possessing Anti-inflammatory Activity. RU Patent 2177793.

[84] Ovodova RG, Golovchenko VV, Shazhkov AS, Popov SV, Ovodov YuS (2000) Structural investigation of pectin and physiological activity of lemnan and pectin from Lemna minor L. Bioorganicheskaya khimiya. 26:743-751.

[85] Ovodova RG, Bushneva OA, Golovchenko VV, Popov SV, Ovodov YuS (2000) Method of Isolation from Vegetative Raw Materials of the Polysaccharides Possessing Immunostimulating Action. RU Patent 2149642.

[86] Gelgay MK, Donchenko LV, Reshetnyak AI (2008) Innovative technology of pectin from secondary sources of raw material after processing coffee. New Technologies. 6:15-18.

[87] Graves F (1994) Process for Producing Pectin Through Ion Exchange. US Patent 5364851. 
[88] Aleinikov IN, Sergeev VN, Rusakov AV, Merkulov YuG (2000) New approach to pectin production. Pishchevaya promyshlennost'. 1: 59-61.

[89] Aimukhomedova GB, Shelukhina NP (1964) Pectin Substances and Their Determination Methods. Frunze: Ilim. 119 p.

[90] Babkin VA, Ostroukhova LA, Ivanova NV, Malkov YuA, Ivanova SZ, Onuchina NA (2002) Phytocomplex of Antioxidant Activity and Production Method Thereof. RU Patent 2188031.

[91] Shelukhina NP, Abayeva RSh, Aimukhomedova GB (1987) Pectin and Parameters of its Production. Frunze: Ilim. 91 p.

[92] Kaisheva NSh, Shcherbak SN, Kompantsev VA, Krikova NI, Ivanova LI (1994) Analysis of protective action of pectins. Zhurnal analititcheskoi khimii. 49: 1158-1162.

[93] Babkin VA, Ivanova NV, Trofimova NN, Es'kova LA, Salyaev RK, Nurminski VN, Korzun AM, Feoktistova LP, Sapozhnikov AN, Lykhoshvai EV, Arsent'ev KYu (2010) Isolation of Pectin, Possessing Membrane Stabilizing Activity and Ability to Reduce Silver Ions, from Larch Wood. Silver Nanocomposites Stabilized by Pectin. RU Patent 2403263. http://www.nti.lin.irk.ru/bibl/rese.asp?n=2156\&s=10 Accessed 29 June 2009.

[94] Nakanisi K (1965) Infrared Spectra and Structure of Organic Compounds. Moscow: Mir. p40.

[95] Odonomažig P, Balga D, Ebrigerova A (1992) Structures of pectin polysaccharides isolated from the Siberian apricot (Armaniaca sibirica Lam.). Carbohydrate Research. 226: 353-358.

[96] Grigoriuk GP (1998) Pectins from a bark of coniferous trees as biologically active components of food stuffs in the medical and practical purposes. In: International Conference on Natural Products and Physiologically Active Substances, 30 November-6 December 1998, Novosibirsk; Russia. p79.

[97] Kondratyuk TA (2009) Production and quality estimation of food products from Siberian larch bark. Abstract of PhD thesis; Krasnoyarsk: Krasnoyarsk State Trade and Economic institute, Russia; Kemerovo, 2009.

[98] Ministry of Agriculture of the Russian Federation. Manual on pectosorbitol application in veterinary. Registration PSP-2-2.0/00344. :Council on Veterinary Drugs of the Ministry of Agriculture of the Russian Federation.

[99] Lipson G, Still G (1972) Powder radiographinterpretation. Moscow: Mir. 384 p.

[100] Babkin VA, Ostroumova LA, D'yachkova SG, Svyatkin YuK, Babkin DV, Onuchina NA (1997) The complex wasteless Siberian and Dahurian larch biomass processing echnology. Khimiya v Interesah Ustoich. Razvit. (Chemistry for Sustainable Development) 5: 105-115.

[101] Levin ED, Denisov OB, Pen RZ (1978) Kompleksnaya pererabotka listvennitsy Complex Processing of Larch). Moscow: Lesnaya promyshlennost'. 224 p.

[102] Tsvetaeva IP, Yur'eva MK (1960) About water soluble larch wood substances. Izvestia Vuzov. Lesnoi Zhurnal. 1: 148-151.

[103] Fengel D, Vegener G (1988) Drevesina (Khimiya, ul'trastruktura, reaktsii) (Wood: Chemistry, Ultrastructure, Reactions)). Moscow: Lesnaya promyshlennost'. $512 \mathrm{p}$.

[104] Trofimova NN, Bichevina OB, Babkin VA (2004) The carbohydrates of the larch cellolignin. Khimiya rastitel'nogo syr'ya. 3: 11-14. 
[105] Bichevina OB, Trofimova NN, Babkin VA (2001) Study of the aqueous prehydrolysis of cellolignin from Larch wood. In: Problems of Sustainable Regional Development, Abstracts of the Second School Workshop of Young Scientists of Russia, September 1721, 2001, Ulan-Ude, Russia. pp24-25.

[106] Korol'kov II (1978) Percolation Hydrolysis of Row Plant Material. Moscow: Lesnaya promyshlennost'. $263 \mathrm{p}$.

[107] Fisher NP. Use of pentoses for manufacture of fodder yeast. In book: Problems of Using Pentose Containing Row Materials, Proceedings of the All Union Conference. Riga: Izdatel'stvo Akademii nauk Latviiskoi SSR, 1958. pp91-99.

[108] Trofimova NN, Gordienko II, Babkin VA (2005) Dependence of redusing substances yield on acid hydrolysis parameters of larch cellolignin. Khimiya rastitelnogo syr'ya. 4: 25-28.

[109] Glyukoza kristallicheskaya gidratnaya: Tekhnicheskie usloviya (Crystalline Hydrate Glucose: Technical Specification) GOST 97588.

[110] Sharkov VI, Sapotnitskii SA, Dmitrieva OA, Tumanov IF (1973) Technology of Hydrolytic Productions. Moscow: Lesnaya promyshlennost'. 480 p.

[111] Babkin VA, Ivanova SZ, Fedorova TE, Medvedeva EN, Malkov YuA, Ostroukhova LA, Trofimova NN, Ivanova NV (2007) Scientific bases of technology of complex processing of a biomass of a larch. Khimiya Rastiytel'nogo syr'ya 3: 9-21.

[112] Nikitin VM, Obolenskaya AV, Shchegolev VP (1978) Wood and Cellulose Chemistry. Moscow: Lesnaya promyshlennost'. 368 p.

[113] Rogovin ZA (1972) Khimiya tsellulosy. Moscow: Lesnaya promyshlennost'. 520 p.

[114] Trofimova NN, Babkin VA. (2003) The cellolignin residue of a larch wood as a drug for obtaining of a crystalline glucose. Khvoinye Boreal'noi Zony. 1: 116-122.

[115] Gert EV, Shishonok MV, Torgashov VI, Kaputskii FN (1988) Effect of dinitrogen etroxide on the structure and properties of cellulose. 8. Recrystallization of amorphous cellulose in the medium of nitrogen oxide (IV) and nitric acid resulting in the formation of the knecht compound. Khimiya Drevesiny (Wood Chemistry). 5: 52-56.

[116] Trofimova NN, Malkov YuA, Bichevina OB, Kurets IZ, Babkin VA (2003) The nvestigation of the sellulose hydrolysis pulp inversion process. Khimiya Rastitel'nogo syr'ya. 4: 11-15.

[117] Glazkova EL, Lebedev NV (1960) Sbornik trudov VNII, no. 8. 235 p;

[118] Kurets IZ, Trofimova NN, Bichevina OB, Belonogova LN, Kashaev AA, Babkin VA 2003) The characteristics of glucose complex with sodium chloride crystals by X-Ray power diffraction and X-Ray stuctural analysis methods. Khimiya Rastitel'nogo syr'ya. 2: 15-18.

[119] Trofimova NN, Babkin VA, Chemeris MM (2002) Catalyzed steam hydrolysis of the cellolignin residue of a larch wood. Khimiya Rastitel'nogo syr'ya. 2: 53-56.

[120] Trofimova NN, Babkin VA (2010) Study of the acid hydrolysis of polysaccharides from arch wood for obtaining crystalline glucose. Russian Journal of Bioorganic Chemistry. 36(7): 847-852.

[121] Lowry OH, Roosebrough NJ, Farr AL, Randall RG (1951) Protein measurement with the Folin phenol reagent. Journal of Biological Chemistry. 193:265-275. 